Florida International University FIU Digital Commons

4-10-1995

\title{
Nursing case management : a new perspective to caring for patients with hip fracture
}

Beverlin Marie Allen

Florida International University

DOI: $10.25148 /$ etd.FI13101585

Follow this and additional works at: https://digitalcommons.fiu.edu/etd

Part of the Nursing Commons

\section{Recommended Citation}

Allen, Beverlin Marie, "Nursing case management : a new perspective to caring for patients with hip fracture" (1995). FIU Electronic Theses and Dissertations. 1226.

https://digitalcommons.fiu.edu/etd/1226 
Florida International University

Miami, Florida

Nursing Case Management: A New Perspective to Caring for Patients with Hip Fracture.

A thesis submitted in partial satisfaction of the requirements for the degree of Master of Science In Nursing

by

Beverlin Marie Allen 
To: Acting Dean Jacquelyn Hartley School of Nursing

This thesis written by Beverlin Allen entitled Nursing Case Management: A New Perspective to Caring for Patients with Hip Fracture, having been approved in respect to style and intellectual content, is referred to you for judgement.

We have read this thesis and recommend that it be approved

$$
\begin{aligned}
& \text { Douglas Coffld, PhD } \\
& \overline{\text { Vando, E. White, PhD, }} \\
& \overline{\text { Luz Fofter, PhD Májor Professor }}
\end{aligned}
$$

Date of Defense: April 10, 1995

The thesis of Beverlin Allen is Approved

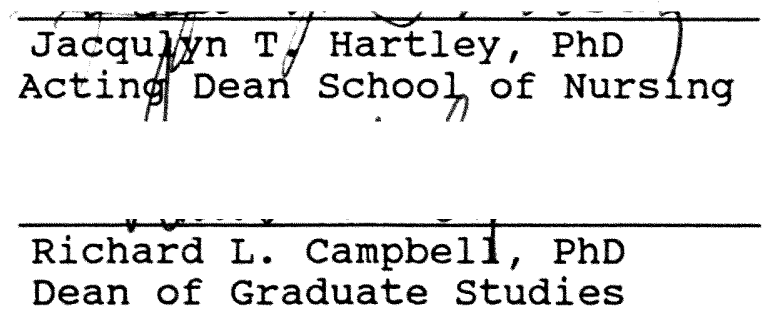

Florida International University, 1995 


\section{DEDICATION}

In loving memory of my mother, Miriam Bailey, who was a great source of inspiration in my quest to knowledge and persuit for excellence. I dedicate this thesis to my husband, Walcott Allen, whose support and unparalleled understanding had made it possible for the completion of this great journey in my education. This is also dedicated to my three daughters, Georgette, Tenecia, and Farah. Thank you for being there for me, I did it all for you. 


\section{ACKNOWLEDGEMENT}

The author thanks the following individuals: Dr. Luz Porter, my Major Professor, for her motivation and guidance in the preparation of this project. Your enthusiasm and energy were greatly appreciated. Dr. Douglas Coffin for his assistance during my formative and preparatory stages. Dr. Vandon white for his insight and confidence in my ability. and Dr. Jack Miller for his assistance.

To Cynthia Pasquel, Tenecia Allen, Ricardo Alcala \& John Kennedy, thanks for your support. To Tim Collier, my sincere gratitude for your tolerance and invaluable assistance. 
ABSTRACT OF THE THESIS

NURSING CASE MANAGEMENT: A NEW PERSPECTIVE TO CARING FOR PATIENTS WITH HIP FRACTURE

by

Beverlin Allen

Florida International University, 1994

Miami, Florida

Professor Luz Porter, Major Professor

Nursing Case Management has motivated nurses to examine the effects of care provided to patients, and to devise means of improving this care. The success of this nursing care delivery model is well documented among a variety of acute and chronically ill patients. Utilizing nonparametric ANOVA for comparison of two means, this study investigates the outcome of the implementation of a nursing case management model on an orthopedic unit of a local hospital. A convenience sample $(\mathrm{N}=149)$ of hip-fracture patients for two separate eight months charting periods were used. The first period was pre-case management and the second period was after the implementation of nursing managed care on the unit. Results suggested that nursing case management was effective in reducing the total length of hospital stay and post-operative days significantly. 
TABLE OF CONTENTS

Chapter

Page

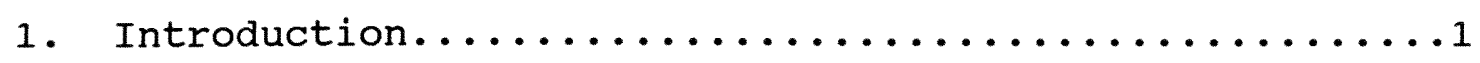

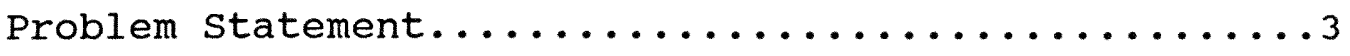

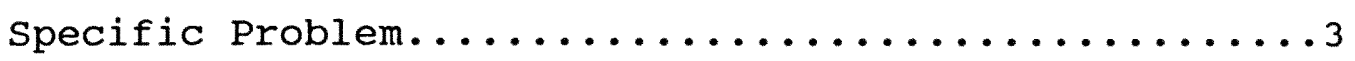

Definition of Terms.......................

Significance of study.....................

2. Review of the Literature.....................

Literature Review.........................

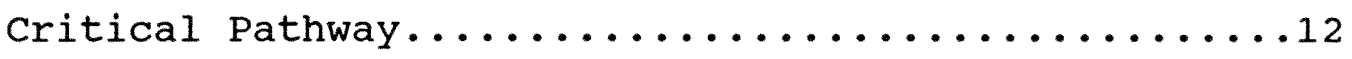

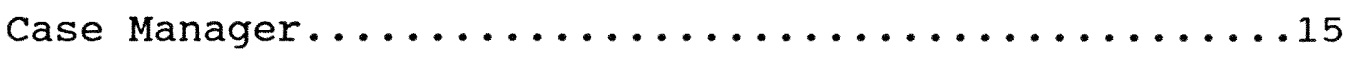

Patients with Hip Fracture need for Nursing.......17

Utilization of Nursing Case Management..........21

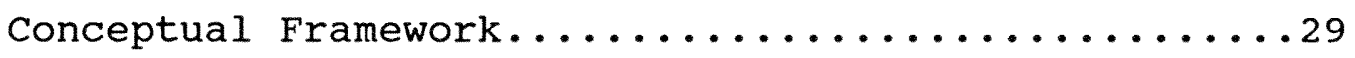

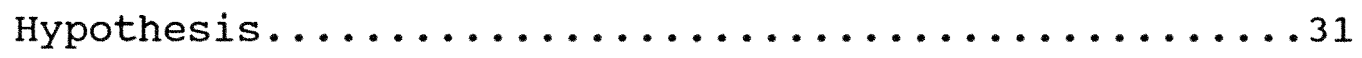

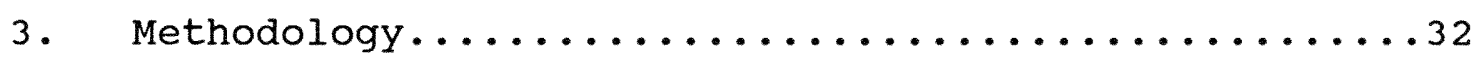

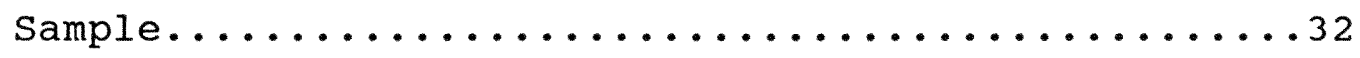

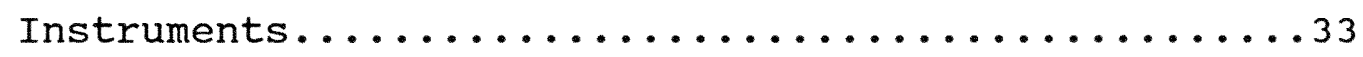

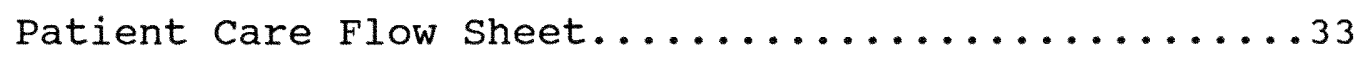

Patient Care Activities and Associated

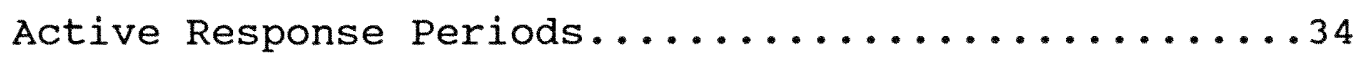

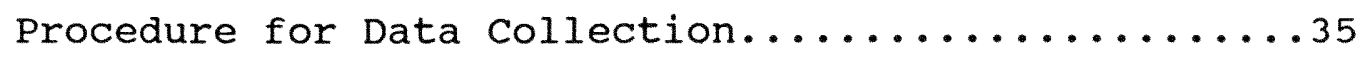

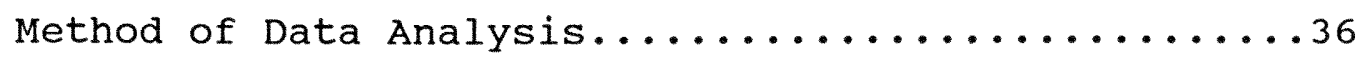


4. Presentation of Findings.................... 38

Demographic Characteristics of Sample...........38 Case Management Impact on Ambulation...........40 Case Management Impact on Activities of

Daily Living.........................

Case Management Impact on Length of

Hospitalization.....................

Summary Test Relating to Case Management Impact

on Patient Care Outcomes..................43

5. Discussion, Conclusion Implication and

Recommendation.....................45

Limitations and Recommendation for Future Research...50

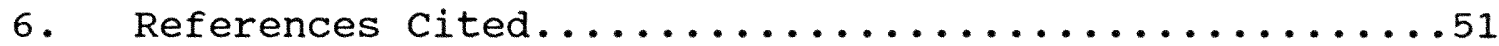

Appendices......................... 58

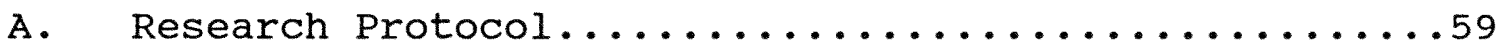

B. Institutional Approval.................68

1 Florida International IRB...............69

2 Mercy Hospital Research Committee............70

C. Research Tools.........................

1 Patient Care Activities and Associated Activity Response Period Sheets.................. 72

2 Patient Care Flow sheet.................

3 Critical Pathway for Hip Fracture Patients......74 


\section{LIST OF TABLES}

Table

1 Frequency Distribution of Subjects by

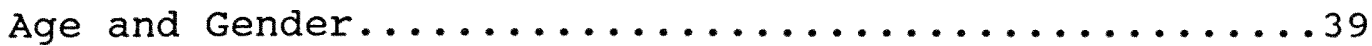

2 Case Management Impact on Ambulation............40

3 Case Management Impact on Activities of Daily Living...............................41

4 Case Management Impact on Length of

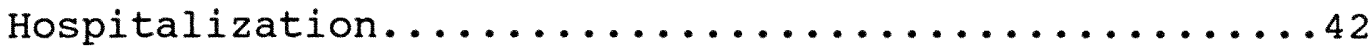

5 Summary Test Relating to Case Management Impact on Patient Care Outcomes ....................44 


\section{CHAPTER ONE}

\section{INTRODUCTION}

The current forty-year trend of increase in the elderly population is projected to continue well into the twenty first century (United states General Accounts office, 1993). It is this group that accounts for the largest percent of patients with hip fractures. As the incidence of hip fractures in the elderly grows, the medical model of health care will fail to adequately address the functional needs of these patients (Reinhard, 1988).

Despite the government's attempts to control costs, total health care spending in 1992 rose by $11.9 \%$ to 838.5 billion dollars - $14 \%$ of the Gross National Product. Although total costs are increasing annually they are still surpassed by hospital expenditures (Nurse Executive, 1993). Patients with hip fractures consume substantial health resources. According to Jetty, Harris, Cleary, \& Campion (1987), patients in the United States, with hip fractures, use more than half of all hospital days devoted to the care of fracture patients.

In October 1983, the Federal Government, cognizant of the problems within the health care industry, implemented its new prospective payment system, using diagnostic related 
groups (DRG) as a basis for payment. Clients hospitalized for hip fractures are now categorized with fees set in advance for each DRG (Grimaldi \& Micheletti, 1985). Currently, there is much pressure to regulate the health care system, mainly because of increasing inflation. Nurses and other care providers must take the challenge to design innovative systems of care delivery that will adequately assist patients and their families through this crisis. Predicated on the belief that a person is an open unique holistic system, subjected to environmental stressors, Newman (1989) predicts that nursing case management might be a most effective and efficient approach to organizing patient care, thereby assisting patients through the pressure of illness. The purpose of this study is to examine the effectiveness of nursing case management (NCM) in improving the quality of life for patients with hip fractures. 


\section{PROBLEM STATEMENT}

\section{GENERAL1 PROBLEM :}

What is the impact of nursing case management upon patients with hip fractures?

\section{Specific Problems: :}

1. What is the effect of case management upon patient outcomes in terms of;

1.1 Ambulation (Am)

1.2 Activities of daily living (ADL)

1.3 Length of hospitalization (LOS)

2. What human or environmental factors enhance the effect of case management upon patient outcomes?

\section{Variables:}

The key variables under study are nursing case management (independent variable) and patient outcomes (dependent variable) measured in terms of ability to ambulate (A), activities of daily living ( $A D L$ ), and length of hospital stay (LOS). Extraneous variables that will be accounted for but not necessarily controlled are age, sex, physical fitness, ethnicity, and other debilitating illness. 


\section{Definition of Terms:}

Case Management: A systematic and coordinated approach to delivery of patient care over an episode of illness in order to improve the quality and efficacy of patient care.

Patient Outcomes: Patient's response to nursing care that is based on knowledge of the usual course of events, and factors relevant to the care of the particular disease process. This is manifested by change in patient's current and future status: measured in related behavior changes, ability to perform activities of daily living, and health knowledge.

Ambulate: The distance walked with or without assistance or assistive devices such as canes or walkers.

Activities of Daily Living ( $A D L)$ : Self care activities that the patient must accomplish each day to meet his/her own needs and the demands of daily life. ADLs include personal hygiene, bathing, dressing, grooming, feeding, and toileting (Smeltzer \& Bare 1992).

Length of Hospitalization: The number of inpatient hospital days for each patient. 


\section{Significance of the study:}

Although the recent increasing focus on health care reform has heightened emphasis on cost of health care, this does not seem to be the only challenge of consumers. Ethridge (1989) found that "consumers are becoming more emphatic about the need to maintain, or in some cases improve, the quality of care that is provided. They are concerned that costs may be reduced without regard to subsequent effect on quality" (p.1). Subsequently, a new system of care delivery is needed to adequately address this predicament.

Nursing case management is suggested as the model of care that could address the needs of consumers, nurses and hospitals. This model of nursing care delivery requires that nurses utilize management skills such as controlling, delegating, directing, and collaborating with patients and other professionals. Such responsibilities could heighten levels of professional accountability as well as afford nurses greater autonomy over patient care. Zander (1985) stated, "assigning and holding the locus of accountability for individualized set of outcomes of nursing care at the staff nurse level will create major advancement in the very culture of nursing" (p.1). Staff nurses could experience greater sense of control and satisfaction regarding their 
care of patients.

orientation of new staff could be facilitated by the utilization of the critical pathway. This allows the orientees to visualize the total picture for the major case type on the unit. Nursing standard of care allows for examination of variances of individual patients. Since these standards are explicit, nurses are likely to become more goal focused.

Hospitals are not paid for clients based on length of hospitalization, rather the hospital gets a fixed amount based on a predicted length of stay for the particular DRG (Reinhard, 1988). Although the financial incentives for expeditious discharge are clear, hospitals could face penalties for clients readmitted for the same problem too soon (Grave \& Kovner, 1986). Obviously an effective monitoring system is needed to minimize such a development. Nursing case management is likely to give administrators, finance officers, and third party payer, concrete evidence that clinicians are actually addressing the most efficient way to provide cost effective quality care for patients. Results of studies done on nursing case management could be a foundation for the improvement of patient care delivery and clinical outcomes per case 


\section{CHAPTER TWO}

\section{LITERATURE REVIEW:}

A variety of issues have motivated nurses to reflect on the lack of empowerment within the profession, and to plan for advancement of professional nursing practice. These include restructuring of healthcare services, reimbursement systems, and consumer demand for effective quality care.

Inspite of this heightened emphasis on healthcare being more competitive with other businesses, nursing has not kept current with this transformation. o'Mally, Loveridge, and Cunningham (1989), observed that "current systems do not possess the depth and sophistication required to manage both the quality and cost component of health care" (p. 29). Consequently, major tasks facing nursing is how to utilize the unique position as the only clinical discipline with the maximum patient clinical contact, to provide safe, cost effective patient care without jeopardizing the stance for quality care.

Nursing must venture to design a model of health care delivery that will simultaneously assure quality of care, patient satisfaction, and cost containment. According to Zander (1987), "the model should keep professional nursing at the pivotal junction of cost and quality, and should 
empower the staff nurse so that he/she can truly be accountable for the clinical and financial outcome of nursing care" (p. 16).

Determining which method of care delivery to be used is still perplexing to many nurses. Christensen \& Bender (1994) observed that $A$ bewildering number of nursing care models have arisen from attempts to design the perfect systems. The dilemma is finding out as to which of these models can provide quality care in a cost effective manner. Beyond the financial concerns, special attention must be directed to finding out which model best focuses attention on patient care and permits professional fulfillment of the nurse. Of the numerous models discussed which include paired practice, patient-focused care, crosstraining, and product line management, case management is the most extensively addressed in hospital and nursing literature.

Nursing case management is suggested as a model of care delivery that restructures the role of nurses so that accountability, continuity, and coordination is fostered among all disciplines throughout the patient's length of stay. This model of care delivery is fast becoming very popular in healthcare circles. Smith (1993) noted that "not since the introduction of primary nursing has such excitement and optimism existed in nursing practice as with 
the introduction of the concept of case management" (p.13). In this scenario, focuses of care are geared towards various issues affecting healthcare resources such as, cost containment, DRGs, and decreasing capital.

Definition of nursing case management has similar connotation for many writers. Pelletier (1990) defines nursing case management as a system of patient care delivery which strategically positions nursing and recognizes the key role that nursing plays in the allocation of resources, consumer perceptions, and overall probability of healthcare organizations. Zander (1985) states that case management is a set of methodology and systems that ensures the attainment of the nursing product with the best outcomes possible for patients and families. Similarly, Ethridge (1989) explains this model of care as a system of patient care delivery that focuses on the achievement of outcomes within effective time frames and with appropriate use of resources. It is viewed as encompassing the entire episode of illness, across settings in which the patient receives care.

Regardless of the various definitions and multiplicity of informations available on case management, there is little scientific research documented. However, this has not dampened the enthusiasm of advocates of this model of nursing. Ethridge (1989) affirms that although the worth of case management is still unclear, the preliminary data is 
positive yet not conclusive. "However, there is enormous worth in any process that finally identifies physician and nurses as accountable for the financial and clinical outcomes of patient" (p. 37). Nursing case management is proposed as the system of care that will stimulate nurses to futuristic ideas. Goals are designed to facilitate outcomes based on standard of care. These include well-coordinated continuity of care through collaborative practice patterns, efficient use of resources to reduce wasted time, energy and materials, timely discharge within DRG length of stay, professional development and satisfaction without jeopardizing the quality of care delivery (Brower, 1988, Zander, 1988, \& Peirog, 1991).

The case management concept is not unfamiliar to nursing, rather, it reinforces established nursing role. According to Ward- Evans, Hodges, \& Smith (1991), case management has been a dimension of practice since 1863. A form of case management was used in 1895 by pioneers of nursing such as Lilian Ward, and Mary Brewster, who provided in-home services to individuals referred by doctors or families. Nurses coordinated the care of patients with their physician, if they had none, nurses would call upon one. The nurses also arranged available resources for the poor, and hospitalization of their clients when necessary 
(Kalisch, \& Kalisch, 1986).

Despite this rich history, the nursing role has not progressed in health institutions. Zander (1987) observed that, although historically nurses have been the managers of care in the hospital, their perspective was usually the management of care for the crisis, the shift, or the stay in a given geographic unit. Essentially, this stems from the way nurses perceive themselves as task workers, which limits their authority and weakens their image. Furthermore, "the inherent strength of nursing seems to be lost in roles which have tremendous responsibility, but impoverished authority within the healthcare institution" (p. 16). Over the years, the nursing case management role has progressed from community to hospital and back to community.

According to Smith \& Danfort (1994), the pioneering of today's hospital-based case management is credited to the New England Medical Center (NEMC) in Boston, MA. Concepts from primary nursing have been expanded and New England Medical Center continues to be a motivating force in the promotion of case management among hospitals. It seems ironic that the nursing challenge is the same today as almost ten years ago when Twyon (1985) declares that nursing's very real challenge in 1985 was to move from a traditional posture of responding to external demands to a position that would influence changes in the healthcare 
system. Although, this change was seen as indeed, a quantum leap it was one that nursing must make because it was necessary and there was one is in a better position to do it particularly in the inpatient area.

Nursing case management is proposed as the strategy for challenging existing predicaments in healthcare. The unique role that nursing plays in its development has the prospect of achieving the recognition for which the profession strives.

\section{Critical Pathways.}

Like many other health care providers, critical pathways form an integral path of the nursing case management at Mercy Hospital in Miami Florida. Millenson (1988) describes critical pathways as the tool used by case management teams to collaborate and communicate with staff and with others. Development of this tool for each case type has marked an important step in nursing case management.

Giffin \& Giffin (1994) found that the critical pathway concept which originated in the late 1980's from work done at the New England Medical Center, has evolved into an inter-disciplinary tool, facilitating coordination of care among multiple clinical departments and care-givers, and more recently, across multiple delivery settings. Various 
definitions of critical pathways exist.

Zander (1987) explains that critical pathways are abbreviated versions of case management plans showing the critical or key incidents that must occur in a predictable and timely fashion to achieve an appropriate length of stay. Categories of key incidences of a critical pathway are consults, diagnostic tests, activities, treatments, diet, medications, discharge planning and teaching.

specifically, critical pathways promote the identification of specific outcomes, process, and resources by case type. Nurses and doctors express little difficulty in developing critical pathways because this process simply requires that they outline their work. This allows nurses and other healthcare workers to plan and anticipate outcomes.

Although, critical pathways take existing information and makes it more useful to practitioners, it is suggested that development of the plan can be costly and time consuming, especially with regard to commitment of staff time for the successful implementation of a program. Additionally, a multi-diciplinary team is needed to research, develop, and implement each pathway. Comprising the team should be staff from every department which plays a role in the patient's care for that diagnosis. Participating disciplines include: physical therapy, dietary, nursing, 
occupational therapy, laboratory, respiratory, utilization, administration, quality assurance, and physician. The team is also responsible for reviewing and updating the pathway once it is in place.

The proposed benefits of critical pathways to nursing are many as noted by Metcalf (1991). These include assurance of quality care while maintaining consumers satisfaction, early problem identification, examination of over-use and under-use of resources as well as early discharge planning. As the patient's care proceeds, actual care is compared with the expected plan of care. Deviation from the expected patterns are recorded as variances. For example, patients with hip surgery are out of bed by the second post-operative day. Failure to accomplish this is recorded as a variance.

The case manager in consultation with the physicians evaluate the variances. Modifications of the plan are made where required. Ethridge (1989) elucidates to three sources of variances - system, client, and patient. System variance occurs when, for example, physical therapy is not initiated on time due to not enough therapist on a particular day resulting in delayed discharge. An example of clinicians variance is found when a haemoglobin is required on Day two but is not ordered or obtained. Patients variance is exemplified by a patient developing a deep vein thrombosis 
which results in prolonging the length of hospitalization.

\section{Case Manager:}

For any system to be effective, it is advantageous to have someone who is accountable. Similar to a gate-keeper, the nursing case manager actualizes and orchestrates the case management process. Much controversy still exists in healthcare circles as to who should be the case manager. Suggestions included the social worker, the doctor, and the utilization review coordinator. Still others firmly believe that the nurse is the person, who spends the most time with both patients and relatives so is best prepared to be the case manager.

Ethridge (1989) advocated that the staff nurse case manager is the person who makes the system work for patients families, and physicians. As a primary care giver, the nurses as the case manager in a key position to adapt policies, procedures and to note any variance in the patient's progress determined by the critical path.

The role of the nurse case manager includes collaborating with the health care team and patient in ensuring effective use of resources, establishing standards and meeting outcomes within an appropriate length of stay. o'Mally (1992) noted that central to the case manager role is accountability for managing clinical care across 
departmental, service, and program lines as well

fluctuations within the health care system. Moreover, it is the responsibility of the nurse case manager to ensure that variations based on a patient's individual needs are merited and well documented. For example, the nurse case manager strives for clinical goals such as maintenance of skin integrity; functional goals such as a patient performing activities of daily living; and social goals such as a family learning how to care for incisional site. Expected outcomes are both personal and professional rewards as patient care improves and staff nurses become more proactive.

O'Mally (1992) argues that today's nurse desires expanded career opportunities, empowerment with participation in decisions affecting his or her practice, more recognition by physician colleagues, and higher status within the health care organization. Nursing case management has been shown to facilitate nurses demonstrating creativity in leading the healthcare team to a more progressive model of patient care delivery, with measurable benefits for all.

Development of the case manager's role is vital to nursing and to the enhancement of the profession. Zander 1985 noted that until nursing has delivered clinical outcomes per "case" and developed a case manager who is 
accountable for their actualization, we will not achieve the clarity, stature, or viability that our patients, their families, our colleagues, communities, and institutions so urgently need from our profession.

\section{Patients with Hip Fractures: Need for Case Management.} Review of the literature indicates that much success has been achieved by using case management for some case types. However, little research has been documented on the utilization of case management model for hip fractured patients. Yet, in 1985 an annual incident of 200,000 hip fractures were reported, and predictions of a rise to 330,000 in the next 15 years. Further predictions indicate that by the year 2050, there will be 650,000 cases of hip injures per year, with half of those injured above the age of 85 years ( Brody, 1985).

The population in the United States over age 65 is growing rapidly and will increase from $12 \%$ to $20 \%$ by the year 2025 (National Institute on Ageing). The magnitude of this situation makes it imperative that immediate steps be taken to develop a clear understanding of fractures, and the process involved in the management of patients with hip fractures. In her definition of fracture, Hansel (1988) states that a fracture is a break in the continuity of a 
bone.which occurs when more stress is placed on a bone than it is able to absorb. Most fractures are the result of trauma. Any one who acquires one or more fractures therefore, has to make rapid and often long-range adjustments in his/her pattern of daily living. Although not always apparent, hip fracture is an acute, devastating often fatal event for many people. Nineteen percent of patients die within six months of their injury (zindrick, Daley, \& Holleyfield, 1985). Care of these patients requires specialized nursing care based on scientific principles regarding fractures and the fracture healing process. ( Hansel, 1988).

Recent studies done on hip fracture patients have shown that the incident of hip fracture is increasing rapidly with age so that the incident doubles every five years after age fifty (Bower, 1960: Jensen, 1980). The exact cause of hip fracture varies, and in many cases are unknown. Yet, there are many associated factors such as osteoporosis, decreased estrogen levels in women who are postmenopausal and who have had bilateral oophorectomies, low levels of physical activity, low dietary calcium, inadequate levels of vitamin $\mathrm{D}$ and its metabolites, high levels of dietary protein, caffeine consumption, alcohol consumption, and cigarette smoking (Kelsey \& Hoffman 1987).

Although the management of this kind of injury varies 
from institution to institution and among physicians, Hansel (1988), contends that there are three principles of treating fractures which are reduction or realignment of bone fragments, maintenance of realignment by immobilization and restoration of function. Because hip fracture leads to high mortality in the elderly, surgical repair of the fractured hip is becoming the most common surgical procedure for patients, especially, over 85 years old (Farmer, White, Brody, \& Bailey, 1984).

Once the hip has been repaired, the major problems facing patients with hip fractures are functional rather than medical needs. Many people have difficulties performing basic activities of daily living for at least six months (Lukens, 1985). Therefore, caring for the hip fracture patients requires the combined principles of both orthopedic and geriatric nursing. Timely nursing interactions are essential and are based on knowledge of the specific need of the elderly from arrival in emergency through recovery.

The primary nursing goal is to assist the patient to achieve an optimum level of health and resume his roles in the home, family, and community. These goals should be based on realistic expectations. Hansel (1988) found that the specific aims of treatment are to relieve pain, obtain and maintain satisfactory position of the fractured 
fragments, allow and, if necessary, encourage bony union, and restore optimum function not only in the fractured limb but the whole human system.

Barangan (1990) supports this by postulating that, for the elderly patient with a hip fracture the goals of nursing are to maintain or restore function within the patient's ability and prevent increased disability. These goals are achieved through appropriate and timely nursing activities. Additionally, efforts to identify factors that contribute to recovery as well as prevent disability in hip fracture patients should begin with a comprehensive patient assessment. Supplementary goals will include physical therapy to maximize, the lower extremity strength, and to progress to optimum range of motion. Reinforcing small gains can be helpful in keeping the patient motivated despite perceived slow progress.

Most hip fracture patients are out of bed within 24 hours of surgery. The first activity is usually a bed to chair transfer. Gradually, the patient progresses from ambulating short distances with assistance, then to full ambulation. According to Twyon (1985), nurses are responsible both for task and outcomes of their care. Consequently, they must be able to explain the nature of their work, and what there contributions to the individual patient are in very concrete terms. Nursing diagnoses must 
be meaningful. Nurses must look at the variables in a patient hospital stay in which nursing has the biggest impact. These relate to dependency, knowledge, mobility, and nutrition. An experimental study is in order to determine if length of stay can be reduced through nursing intervention. Nursing case management has the capability to afford nurses this opportunity.

\section{Utilization of Nursing Case Management.}

Nursing case management was first developed at the New England Medical Center in Boston, Massachusetts, as a direct response to the economic pressures exerted on hospitals, specifically by DRGs. This has provoked other healthcare institutions to begin the exploration and subsequent implementation of systems which would improve the quality and cost of patient care.

Although many institutions are just beginning to utilize this concept of nursing case management, Zander (1988) reported that positive results existed as early as 1986. Examination of the management of ischaemic stroke patients using case management and critical pathways, revealed both quantitative and qualitative findings. Data showed a $29 \%$ drop in the length of stay and a $47 \%$ drop in the average number of intensive care unit days. The decreased ICU stay increased quality by maximizing the 
sensor deprivation experienced by patients in those settings. Patients were able to transfer out of ICU seven to ten days earlier than usual.

Similarly, in 1987, Hillcrest Medical Center initiated nursing case management in an effort to provide the best care at the lowest cost while using existing resources. This 646-bed hospital in Tulsa, Oklahoma had 190 DRGs, 106 of which were case managed. In 1988, results showed about $\$ 960,000$ of billed charges and 430 patient days were saved through the nursing case management program. overall findings were early patient discharge or discharge within appropriate length of stay, expected or standardized clinical outcome, promotion of collaborative practices and coordinated continued care (McKenzie, Torkelson \& Holt, 1989) .

Funded in 1989 by a grant known as the Nursing Incentive Reimbursement Award (NIRA), the New Jersey Department of Health challenged New Jersey hospitals to develop a system of care that would not only improve quality but increase nurses satisfaction and professional responsibility. Nursing case management was chosen in an effort to explicate the prioritization of goals with patients and families, collaborate with attending and interdepartmental levels, understand the DRG system of reimbursement; as well as impact the quality documentation 
on financial reimbursement. Findings suggested cost savings and reductions in length of stay (Kovner, Hendrickson, Knickman \& Finkler, 1993).

Comparison data for case management and non-case managed patients undergoing hip surgeries were generated in a study done by strong (1986). Findings indicated that case management patients had an average length of stay of 8.1 days in comparison to an average length of stay of 10.2 days for non-case managed patients. Reduction in LOS was accomplished even though nursing case-managed patients had a higher average acuity (4.4) (Ethridge, 1989).

Metro Health Medical Center (MHMC), a large urban teaching facility, is a Level 1 trauma center which serves a multicounty area. In 1989, the Medical Director of orthopaedics recognizing that there was fragmentation of care within their department, implemented nursing case management. They found that the benefits were improved communications among disciplines, clearer delineation of role expectation, and development of a more collaborative work team. Consequently, patient care was promoted and became more coordinated. The author explained that Betty Newman's Systems Model of Care was particularly useful as case managers were able to identify systems stressors and act appropriately to promote positive outcomes (Mann, Hazel, 
\& Geer, 1993).

According to Metcalf (1989), Alliant Health System, a not-for-profit corporation based in Louisville, Kentucky, owns and operates Norton Hospital, a 375-bed, tertiary adult acute care facility, Kosair Children's Hospital, a 227-bed pediatric acute care facility, and Methodist Evangelical Hospital, a 372-bed adult general acute care facility. Between 1989 to 1990 , results of critical path process show a decline in average length of stay for joint replacement patients of 2.6 days with an average charge per case saving of $\$ 2,136$ compared to 1989 charges. Findings further suggest that there were many advantages to orthopaedic patients including more organization of care, decrease charges per case, and reduced length of stay while still maintaining quality care. Results of this study not only identify areas for improvement of care but reflected increased multidiciplinary collaboration among nurses, physicians, and ancillary departments.

st. Margarets Mercy Health Care Center in Dyer, Indiana, initiated a critical path for total hip and knee replacement in 1990. Since then, the Los has dropped to five days from 11.7 days. The same path was introduced at the hospital's north campus in Hamond, Indiana, in 1992. According to sources from that center, reported benefits from critical path implementation include reduction in 
length of stay to eight days from 14.2 days for total hip, reduced resource utilization, lower cost, improved patient outcome, and more collaborative patterns (Giffin \& Giffin, $1994)$.

In like manner, Harper Hospital, a 700-bed tertiary care facility in Detroit, MI, reported comparable findings. Data indicated that patients were very satisfied with nursing case management. Physicians satisfaction increased as they gained better understanding of case management, and length of stay (LOS) was decreased by approximately two days (Cronin \& Maklebust, 1989).

Westmead Hospital in West Sydney utilized the opportunity to evaluate the effectiveness the nurse case manager in a study of fractured hip management program in 1993. This was part of a Commonwealth Government funded initiative incentive to increase hospital efficiency. Under this programme money was top-sliced from budget allocation to state governments and allotted to projects designed to reduce reliance on in-patient beds either by reducing admissions or by reducing length of stay. Evaluation of this program found that patients receive surgery sooner and spend less time in the hospital without adverse effect on outcome. Findings of this study suggest that recognition of the role of the nurse as patient advocate and case manager can lead to more cost effectiveness as well as higher 
quality care (Shiell, Kenny \& Farnworth, 1993).

Grayheal, Green, Mckenia (1993) reported that overlake Hospital Medical Center in Washinton developed a multifaceted case management model. Objectives embraced improved clinical and financial outcomes for elected patient population, including Total Hip Replacement. Findings suggest both clinical and financial outcomes, namely, reduction in admission rates, decreased complications, financial outcomes measured in reduced length of stay and cost relative to reimbursement. Besides, case managers at Monticlear Baptist Medical Center (MBMC) in Birmingham, Alabama have been able to steadily decrease organizational operating expense, anticipate problems, and solve specific individual patient situations.

The Eastern Region of the Group Health Cooperative of Pueget Sound (GHCPS) has managed 88 total hip and total knee replacement under the pathway it began using in september 1993. Reported benefits include development of a systemic approach to patient education and reduced length of stay for these patients (Giffin \& Giffin, 1994).

Case managers at Hennepin County Medical Center in Minneapolis were not only responsible for more than $\$ 1$ million dollars of direct cost savings, but decreased readmission rates of patients having major bowel procedures 
from $67 \%$ to $26 \%$, and patients having cardiovascular disorders (except TIA) from $43 \%$ to $31 \%$. They even increased compliance with antibiotic protocols in their patients having hip and femur procedure from $38 \%$ to $89 \%$ (Zander, $1994)$.

According to Wimpsett (1994), Immanuel St. Joseph's Hospital, Mankato, Minnesota, used a team approach to develop and maintain a patient-focused service for the patients receiving total joint replacement. Issues and barriers to quality and cost effective care were identified, many of which were unique to the region. Among the identified issues longer length of stay (LOS), low reimbursement for some DRGs, duplication of equipment and supplies, waste, misuse, abuse of resources, delays and cancelled surgeries. Studies done suggest that nursing case managed groups met their independence goal from 0.4 to 0.7 days earlier. There was also improved staff and patient satisfaction, as well as increased team collaboration. Cost savings were reflected in the decrease inpatient days, delays and cancelling of surgery, as in the duplication of testing and supplies. These outcomes were maintained throughout 1993 with LOS decreasing by another day.

Although Zander (1988) reported that only $15 \%$ of hospitals in America were using or exploring case management 
concept, critical pathways are currently sweeping the nation's hospitals and integrated healthcare systems. Reports by surveys published in hospital and network magazines, indicated that $60 \%$ of hospitals have adopted critical pathways or similar modalities. These include Good Samaritian and Friendly Hills Health Care Network in Southern California (Giffin \& Giffin, 1994).

Local sources affirm that many hospitals in Miami have adopted a form of nursing case management. Among them are Jackson Memorial Hospital, Mercy Hospital, Baptist Hospital and Cedars Hospital. As institutions become increasingly aware of the need for an intrastructure for the internal regulation of processes in order to create desirable costs and outcome, it is anticipated that the role of nursing case management will continue to evolve.

The literature review roaringly attests to the use of nursing case management as a possible effective method of managing certain case types. Much emphasis has been placed on the benefits related to the cost component of care however. This study seeks to examine nursing case managements effectiveness on improving the quality of life for patients with hip fractures. 


\section{CONCEPTUAL FRAMEWORK}

The framework underlining this study is derived from Betty Newman's Healthcare systems model which uses a total person approach to patient problems. According to this persons are unique, dynamic, holistic beings, who possess normal characteristics and responses. Human beings are constantly interacting with their internal and external environments thereby are subjected to stressors present in the environment. Stressors can disrupt individuals' normal Iines of defense which have developed over time. According to chinn \& Kramer (1991):

The system's model is based on an individual's relationship to stress, the reaction to it, and reconstituting factors that are dynamic in nature. The nurse assesses, manages and evaluates patient systems. Nursing's focus is on variables that affect person's response to stressors. Assessment of individuals' consider knowledge of factors influencing a patient's perceptual field, the meaning stressors have to patients as validated by patient and care giver, and factors the care giver believes influences the patient situation. Nursing acts to impede or arrest an entropic state, or a state of disorder and 


\section{disorganization. ( p.184)}

Many stressors accruing in the orthoaepedic population are related to trauma, unplanned admission, multiple surgical problems, psychological adjustments, and post discharge lifestyles changes (Mann, Hazel, Green, Huley 1989). Additionally, patients recovering from hip surgeries are particularly stressed by the possibility of forced personal dependence and of sustaining another fall. Nursing case management activities are, therefore, directly related to eliminating fragmentation and disorganization of care, thereby, reducing stress for patients and families.

Newman's System model of care was utilized with orthoapedic patients at Metro-Health Medical Center (MHMC) in Cleveland. This Level 1 trauma center which provides a full range of orthopaedic services, found that Newman's system model of care encompasses levels of prevention which strengthens lines of resistance and hence, lessen the impact of stressors on a system's integrity.

The primary prevention role of the case manager is to identify and eliminate environmental stressors, thereby decreasing the probability of patients encountering stressor. In secondary prevention, the role looks to manage hospital patients who are potential DRG's outliers and attempts to decrease length of stay by assessing rehabilitation, home, and ambulatory supports. In tertiary 
prevention the case manager's role closes the patient care circle by facilitating discharge planning and post-discharge care (Mann, \& Hazel, 1993). This conceptual framework leads to the formulation of the research hypothesis hereby presented.

\section{Hypothesis:}

Based on the theoretical framework described above, it is hypothesized that:

1. Nursing case managed will be able to ambulate earlier than non- nursing case managed patients.

2. Nursing case managed patients will perform activities of daily living earlier than nonnursing case managed patients.

3 Nursing case management patients will have shorter hospital length of stay than non-nursing case management patients. 


\section{CHAPTER THREE}

\section{METHODOLOGY}

To determine the possible effects of nursing case management on patient outcomes (PO) and length of hospital stay (LOS), the investigator conducted a retrospective study based on chart review. The research design and methodology used are described in this chapter.

\section{Sample:}

The population consisted of all patients with a diagnosis of hip fracture admitted to a local south Dade Hospital. The control group comprised of all patients confined in this hospital during the pre-case management period, from January to September 1990. Similarly, the experimental group consisted of all hospitalized patients during the nursing case management period, spanning from January to september 1994. Patients with co-morbidities such as altered mental status and chronic obstructive Pulmonary Disease (COPD), Parkinsons Disease, Morbid Obesity, and amputation of the leg were excluded from the study, as these diagnoses could affect the results of the study. Because 1991 to 1993 were years of heightened awareness and planning for case management, this period was not included in the study. 


\section{Instrument}

\section{Patient Care Flow'sheet:}

This was developed at a local South Dade Hospital in the late 1980's to be used by nurses for the assessment and recording of patient activities and equipment used in their management. The patient care Flow sheet is divided into nine sections with columns designated for all three shifts. Through use of this tool, the nurses can quickly and comprehensively record the patient's status in terms of nutrition, hygiene, activity, elimination, safety, and sleep. Also included on this sheet are spaces for documenting intravenous therapy, support measures and treatments such as: oxygen therapy, walkers, and crutches.

on the alternate side of the patient care flow sheet is the systems assessment sheet for each shift. This tool is employed in the documentation of evaluation pertaining to musculo/skeletal, neurological, cardiovascular, respiratory, skin, gastrointestinal, urinary, and psychosocial/sexuality of individual patients. Findings are recorded as "yes" or "no" by placing a check mark in the applicable column. Also present on both sides of the record is a place for signatures of nurses for the various shifts.

This tool has been used in this facility for many years and has existed in both the case management and non- case management periods. Reports from nurses indicated that the 
use of this tool has not only significantly reduced the amount of time spent on nursing documentation, but it has greatly enhanced systematic and comprehensive patient assessment. Each patient care flow sheet is used for 24 hours only and forms a permanent part of the medical record. A copy of this tool is presented in appendix B.

\section{Patient Care Activities and Associated Response Periods} (PCAARP) .

The Patient Care Activity and Associated Activity Response Period tool is designed to collect and compile the data obtained from patient records. This tool was used for collecting background records of subjects pertaining to age and sex. It allows for the on-going assessment of activities of daily living such as complete feed, feed with assistance, self feed, complete bath, bath with assistance, and self care. Patients' ability to ambulate was recorded as bedrest, out of bed with chair, and ambulate. Also noted in this tool are admission dates, surgery dates and discharge dates. Activities of daily living are recorded from surgery date to discharge date. Each sheet may be used to collect data on five patients. 


\section{Procedure for Data Collection}

Data were collected once approval of the study was granted by the Institutional Review Board for the Protection of Human Subjects (Appendix B) and permission was granted by Mercy Hospital Research Committee (Appendix B). In an effort to investigate the effect of nursing case management programs since its adoption at this institution, activity periods of eight months in 1990 and 1994 respectively, were selected. Study patients were chosen by convenience from those admitted with a diagnosis of hip fractures. The investigator obtained a list of all patients from the operating room who had repair of hip fracture during the period specified. Since certain pre-existing conditions affect patients' length of stay, ability to ambulate and to perform basic ADLs, certain patients were excluded from the study. These include patients with a history of altered mental status, chronic obstructive pulmonary disease (COPD), amputees, cardiac conditions necessitating monitoring prior to surgery; Parkinson disease and acute morbid obesity. All other patients were included in the study regardless of individual variables such as age, sex, and physical fitness.

Patient's ability to perform activities of daily living were assessed according to the Patient Care Flow Sheets and Systems Assessment Sheets. Particular attention was placed on nutrition, hygiene, musculo-skeletal and neurological 
assessments. Additionally, nursing notes, and physical therapy notes were reviewed as necessary to clarify data. Patients were dropped from the study if the information was not available in these sources. Length of Stay (LOS) was measured by determining the number of days from admission to day of discharge.

\section{Method of Data Analysis}

Data for this study were tabulated into appropriate categories for statical analyses. The population consisted of similar type of patients, similar gender mix and about similar age mix (or older for the 1994 period). To determine the effects of nursing case management on these patients, comparisons were made on the basis of length of stay (LOS), post-opperative days, ability to feed self, bathing activities, and ambulatory activities during the period of 1990 and 1994.

The data were analyzed by non-parametric T-test of the effects of case management and other variables between the two groups. The non-parametric test was used since it was difficult to determine that the sample came from a normal population. Other analysis included frequency distributions by age and gender. Differences between group means were satisfied by T-test. In all analyses, the null hypothesis of no significant difference was tested with alpha $=0.05$. This was compared to a p-value depicted in the ANOVA table. Findings at p-value less than .05 are interpreted as 
supporting the research hypotheses, or showing significant effects of specific variables on given patient care outcomes. 


\section{CHAPTER FOUR}

\section{PRESENTATION OF FINDINGS}

The results of the statistical analyses performed on the research data are presented in this chapter. The demographic characteristics of the sample are described and answers to the research hypotheses are presented.

\section{Characteristics of the Sample}

Table 1 presents detailed descriptions of the frequency distribution of subjects by age and gender. A convenience sample $(N=149)$ of hip fracture patients for two separate eight month charting periods were used. As is common in hip fractures, most of the subjects $(\mathrm{N}=114)$ were women ranging in age from 17 years to 98 years. Female subjects in 1994 appeared older than women in 1990.

Compared to females, male subjects $(\mathrm{N}=34)$ were younger for both time periods. In 1990, the mean age for male subjects was 60.00 years, and in 1994, it was 68.60 . Males varied from 23 to 87 years of age for both study periods. 
TABLE 1: FREQUENCY DISTRIBUTION OF SUBJECTS BY AGE AND GENDER

\begin{tabular}{|c|c|c|c|c|c|c|c|c|}
\hline YEAR & SEX & $\mathrm{N}$ & $\begin{array}{r}\bar{X} \\
Y R S .\end{array}$ & $\begin{array}{l}\text { MIN } \\
\text { YRS. }\end{array}$ & $\begin{array}{l}\text { MAX } \\
\text { YRS. }\end{array}$ & $S T D$ & P-VALUE & $T$-VALUE \\
\hline \multirow[t]{2}{*}{1990} & $F$ & 56 & 73.75 & 17 & 98 & \multirow[t]{2}{*}{16.69} & \multirow[t]{2}{*}{0.03} & \multirow[t]{2}{*}{-2.18} \\
\hline & $M$ & 14 & 60.00 & 23 & 86 & & & \\
\hline \multirow[t]{2}{*}{1994} & $F$ & 59 & 78.80 & 52 & 94 & \multirow[t]{2}{*}{12.27} & \multirow[t]{2}{*}{0.03} & \multirow[t]{2}{*}{-2.18} \\
\hline & $M$ & 20 & 68.60 & 43 & 87 & & & \\
\hline \multicolumn{2}{|c|}{ TOTAL } & 149 & 73.77 & 17 & 98 & 14.48 & 0.03 & -2.18 \\
\hline
\end{tabular}


Case Management Impact on ambulation

Formerly, post operative hip fracture patients were kept inactive for many days. As shown in Table 2 this nodality seems to be changing with the implementation of nursing case management. Findings indicate reduction of time from 1990 to 1994 in all areas relating to patient's ability to ambulate. The maximum improvement was noted in the area of full ambulation. Patients involved in nursing case management ambulated approximately two days earlier than non-case managed patients. The number of days for patients to ambulate varied from 1 to 18 days for non-case managed patients compared to 1 to 13 days for case managed patients. These findings support the hypothesis that nursing case management patients will be able to ambulate earlier than non-case managed patients.

TABLE 2: CASE MANAGEMENT IMPACT ON AMBULATION

\begin{tabular}{|c|c|c|c|c|c|c|c|c|c|}
\hline \multirow{3}{*}{$\begin{array}{r}\text { VARIABLE } \\
\text { BREST } \\
\end{array}$} & \multirow{2}{*}{\multicolumn{2}{|c|}{$\begin{array}{cr}X^{-} & D A Y S \\
90 & 94\end{array}$}} & \multicolumn{2}{|c|}{$S T D$} & \multicolumn{2}{|c|}{$M I N D A Y S$} & \multicolumn{2}{|c|}{ MAX DAYS } & \multirow{3}{*}{$\begin{array}{c}P \\
0.0006\end{array}$} \\
\hline & & & \multicolumn{2}{|c|}{$90 \quad 94$} & \multicolumn{2}{|c|}{$90 \quad 94$} & \multicolumn{2}{|c|}{$90 \quad 94$} & \\
\hline & 2.2 & 1.5 & 1.4 & 0.8 & 1.0 & 1.0 & 7.0 & 4 & \\
\hline CREST & 1.7 & 1.2 & 1.2 & 0.6 & 1.0 & 0.0 & 6.0 & 3 & 0.0031 \\
\hline$A M B$ & 7.0 & 4.6 & 3.2 & 2.4 & 1.0 & 1.0 & 18.0 & 13 & 0.0001 \\
\hline
\end{tabular}

BREST: Bed Rest

CREST: Chair Rest

AMB: Ambulate 


\section{Case Management Impact on Activities of Daily Living}

Table 3 depicts the impact of nursing case management on patient outcomes as relating to the ability to perform activities of daily living. Significant improvements were noted in the area of feeding in 1994, compared to 1990. Maximum improvement was noted in the area of assisted feed, the difference between the two groups being significant at p-value $=0.02$. Complete bath and self bath showed no statistical significance; however, assisted bath showed improvement by as much as two days. These findings lend support to the hypothesis, that participants in nursing case management programs will perform activities of daily living earlier than those who are not involved in this program.

TABLE 3: CASE MANAGEMENT IMPACT ON ACTIVTTIES OF DAILY LIVING

\begin{tabular}{|c|c|c|c|c|c|c|c|c|c|}
\hline \multirow{3}{*}{$\begin{array}{c}\text { VARIABLE } \\
\text { CFEED } \\
\end{array}$} & \multirow{2}{*}{\multicolumn{2}{|c|}{$\begin{array}{rr}X^{-} & \\
90 & 94 \\
\end{array}$}} & \multicolumn{2}{|c|}{$S T D$} & \multicolumn{2}{|c|}{ MIN DAYS } & \multicolumn{2}{|c|}{$M A X D A Y S$} & \multirow{3}{*}{$\begin{array}{c}P \\
0.033\end{array}$} \\
\hline & & & \multicolumn{2}{|c|}{$90 \quad 94$} & \multicolumn{2}{|c|}{$90 \quad 94$} & \multicolumn{2}{|c|}{$90 \quad 94$} & \\
\hline & 1.6 & 1.3 & 1.4 & 0.7 & 1.0 & 1.0 & 9.0 & 5.0 & \\
\hline AFEED & 3.3 & 1.5 & 3.6 & 1.9 & 0.0 & 0.0 & 15.0 & 6.0 & 0.0002 \\
\hline SFEED & 6.0 & 4.7 & 3.9 & 3.0 & 0.0 & 0.0 & 19.0 & 14.0 & 0.033 \\
\hline CBATH & 5.5 & 4.5 & 4.0 & 2.2 & 1.0 & 1.0 & 18.0 & 13.0 & 0.067 \\
\hline ABATH & 5.1 & 2.6 & 3.6 & 2.4 & 0.0 & 0.0 & 18.0 & 9.0 & 0.001 \\
\hline$S B A T H$ & 0.4 & 0.3 & 1.2 & 0.8 & 0.0 & 0.0 & 8.0 & 4.0 & 0.634 \\
\hline
\end{tabular}

CFEED: Complete Feed AFEED: Assist Feed SFEED: Self Feed
CBATH: Complete Bath ABATH: Assist Bath SBATH: Self Bath 


\section{Case Management Impact on Length of Hospitalization.}

With an older population, one would expect that these patients would be sicker and, therefore, would require increased hospital length of stay. However, data presented in Table 4 revealed the length of hospital stay was reduced from 12.12 days in 1990 to 8.2 days in 1994. Minimum to maximum ranges were from 4 to 22 days in 1990 and 3 to 18 days in 1994. Findings also showed significant reduction in the mean post operative (7.5) days for subjects in 1994, compared to 10.9 days for subjects in 1990. Findings supported the hypothesis as results showed that nursing case management was effective in reducing length of stay by $32 \%$ and post operative days by $31 \%$

\section{TABLE 4: CASE MANAGEMENT IMPACT ON LENGTH OF HOSPITALIZATION}

\begin{tabular}{|c|c|c|c|c|c|c|c|c|c|}
\hline \multirow{3}{*}{$\begin{array}{l}\text { VARIABLE } \\
\text { P-OP DAY }\end{array}$} & \multirow{2}{*}{\multicolumn{2}{|c|}{$\bar{X}_{\text {DAYS }}$}} & \multicolumn{2}{|c|}{ STD } & \multicolumn{2}{|c|}{ MIN DAYS } & \multicolumn{2}{|c|}{ MAX DAYS } & \multirow{3}{*}{$\begin{array}{c}P \\
0.0001\end{array}$} \\
\hline & & & \multicolumn{2}{|l|}{90} & \multicolumn{2}{|c|}{94} & \multicolumn{2}{|c|}{$90 \quad 94$} & \\
\hline & 10.8 & 7.5 & 3.7 & 2.59 & 3 & 3 & 22 & 15 & \\
\hline LOS & 12.1 & 8.2 & 3.68 & 2.7 & 4 & 3 & 22 & 18 & 0.0001 \\
\hline
\end{tabular}

P-OP DAY: Post Operative Day

LOS: $\quad$ Length of Stay 


\section{Summary Test Relating to Case Management Impact on Patient Care Outcomes}

Table 5 depicts the overall significant impact of nursing case management on patients activities of daily living, ambulation and length of hospital stay. Based on the $\mathrm{p}$-values it is evident that certain factors such as complete bath and self bath are statistically nonsignificant. However, all other variables lend support to the hypothesis that nursing case management is of paramount importance in the outcomes of patients post operatively. 
TABLE 5 : SUMMARY TEST RELATING TO CASE MANAGEMENT IMPACT ON PATIENT CARE OUTCOMES

\begin{tabular}{|c|c|c|c|c|c|}
\hline VARIABLES & $\begin{array}{c}X_{-90}^{-} \\
(\text {count } \\
=70)\end{array}$ & $\begin{array}{l}\overline{X_{94}} \\
\overline{(\text { cout }}=79)\end{array}$ & p-value & $t$-value & conclusion \\
\hline$A G E M I X$ & 71.0 yrs. & 76.2 yrs. & 0.0302 & -2.18 & significant \\
\hline $\begin{array}{l}\text { COMPLETE } \\
\text { FEED }\end{array}$ & 1.6 days & 1.3 days & 0.0394 & & significant \\
\hline $\begin{array}{l}\text { ASSISTED } \\
\text { FEED }\end{array}$ & 3.3 days & 1.5 days & 0.0002 & & significant \\
\hline SELF FEED & 6.0 days & 4.8 days & 0.0332 & & significant \\
\hline $\begin{array}{l}\text { COMPLETE } \\
\text { BATH }\end{array}$ & 5.5 days & 4.5 days & 0.0671 & & not significant \\
\hline $\begin{array}{l}\text { ASSISTED } \\
\text { BATH }\end{array}$ & 5.1 days & 2.6 days & 0.0001 & & significant \\
\hline SELF BATH & 0.4 days & 0.3 days & 0.6346 & & not significant \\
\hline BED REST & 2.2 days & 1.6 days & 0.0006 & & significant \\
\hline $\begin{array}{l}\text { CHAIR } \\
\text { REST }\end{array}$ & 1.7 days & 1.2 days & 0.0031 & & significant \\
\hline AMBULATION & 7.0 days & 4.7 days & 0.0001 & & significant \\
\hline $\begin{array}{l}\text { POST-OP } \\
\text { DAYS }\end{array}$ & 10.9 days & 7.5 days & 0.0001 & & significan \\
\hline $\begin{array}{l}\text { LENGTH OF } \\
\text { STAY }\end{array}$ & 12.1 days & 8.2 days & 0.0001 & & significant \\
\hline
\end{tabular}




\section{CHAPTER FIVE}

\section{DISCUSSION, CONCLUSION, IMPLICATIONS and RECOMMENDATIONS}

As healthcare providers compete for shrinking resources, means to keep viable and prevent take-overs, many new systems are being tried with varying degree of success (Yong \& Haynes, 1988). However, recent literature suggests that nursing case management has gained increasing popularity in healthcare circles, as many institutions are using this care model for the management of certain case types. This study draws upon other related literature, which points to the importance of collaborative practice. In order for nurses to impact patient care, there needs to be a system that facilities well-coordinated continuity of care through collaborative practice pattern, efficient use of resources, and timely discharge (Brower, 1988, Zander, 1988 \& Peirog, 1991).

As indicated in this study and the review of the literature, most patients admitted with hip fractures are elderly. The preponderance of subjects participating in this study were women $(\mathrm{N}=115)$ with a mean age of 76.34 years. Male subjects $(\mathrm{N}=34)$ had a mean age of 65.06 years. Despite the increase in elderly population for 1994 , findings from this study suggest that patients are more 
active in the case management period than in the non-case management period. These findings concur with the study done by Jetty, Harris, Cleary, \& Campion (1987) on Functional Recovery After Hip Fracture. Older patients were found to be at no greater long-term risk than younger patients for poor functional recovery.

Data from this study indicate that nursing case managed patients have shown significant improvements in performing basic activities of daily living (ADLS), such as feeding and ambulation. Significant statistical findings also support an improved quality of life for patients, since ones self esteem and feelings of helplessness can be greatly improved by being able to perform even this minimum of self help.

Review of the literature suggest that as a consequence of increased activity and increased ambulation, patients independence and sense of well being could be increased. other studies have shown that patients confined to bed for long periods are subjected to increased complications such as deep vein thrombosis, pneumonia, fatigue, depression and decubitis ulcers. Such complications heighten cost and length of hospitalization.

No significant difference in bathing was noted in this study. However, these findings could be attributed to the nurturing nature of nurses, some of whom give credence to bathing patients as a gesture of compassionate nursing care. 
Furthermore, patients recovering from hip surgeries are restrictive in their movements by discomforts and devices which keep the leg in alignment. Such devices as abduction pillows and sand-bags have been shown to hamper maneuvers necessary in the bathing process.

The data in this study strongly support the need for developing timely nursing interventions that are based on realistic expectations. Related literature support the need for nurses to develop comprehensive nursing models which set goals so that patients can achieve an optimal level of health and resume their role in their home, family and community. Hip fractures are devastating, and often fatal events for many patients. Understanding of the implications of this illness should motivate nurses to develop teaching strategies geared to prevent the disabilities and complications of hip fractures.

The findings in this are indicative of the effectiveness of nursing case management model of care in reducing overall length of stay and post operative days. This could be attributed to early discharge planning, which is a key concept in reducing length of stay (LOS). With this process, patients are more knowledgeable of their plan of care, expected progress, and their options for discharge (i.e., discharge home with physical therapy, discharge to a rehabilitation center or discharge to nursing home). 
Necessary referrals are made early in the hospitalization period in order to avoid delays associated with the application process. The impact of decrease in length of stay is a known factor in financial planning and benefit analysis ( Shamian, Hagen, Hu, \& Fogarty, 1994).

Prior to the advent of diagnostic related groups (DRGs), the length of hospitalization was mainly left up to the discretion of physicians. Patients hospitalized for hip fractures were in many cases spending up to three weeks in hospital. The number of in-patient days have been reduced considerably since the implementation of DRGs. However, when compared to community standards, nursing case managed patients spend less time in hospital, have less complications and progress at a much quicker pace than non case managed patients

. The potential financial significance of nursing case management to the institution is related to appropriate utilization of human and financial resources. This reduces current fragmentation of care and facilitates timely discharge. For the consumers of health care it seems to be much more. According to Ethridge (1987) for the patient, nursing case management demystifies and decodes the healthcare delivery system into understandable words and predictable events. It brings the often blurred picture of healthcare into clear sharp focus. 
In an era where much confusion exists as to mode of care delivery, findings from this study could address important professional, financial, and quality-of care issues for nursing. Professional nurses, utilizing nursing case management models, have many care coordination and delegation responsibilities. These nurses must, therefore, be held responsible for clinical outcomes of their care.

Nursing case management effectiveness requires that nurses develop the increased collaborative and bargaining skills necessary to facilitate sharing and communication. Attainment of the goals of case management expounded on in the review of the literature could provide nurses with the structural support necessary to overcome the subordinate role, usually allocated to them in the healthcare industry. Such accomplishments will also enable nurses to achieve the clarity and vibrancy that our patients, families, colleagues, communities, and institutions so earnestly demand of the nursing profession.

Critical evaluation of the research data lends credence to the hypothesis that nursing case management can significantly impact certain patients outcomes. The researcher's own views have been strengthened as it relates to the need to implement changes in approach, attitude and effort in order to keep current with nursing technology of the 21st century. 


\section{Limitations and Recommendation for Further Research}

The limitations of this study are related to the method of data collection which was from a convenience sample. Randomly selected samples are needed to define precisely the outcomes of nursing case management models on patients with hip fractures. This sample was also limited to one institution. Findings could have been enhanced if this study was conducted in more than one healthcare facility. Data from this investigation can be compared with research findings from other institutions. The possibilities of maturation effect accruing could be reduced by conducting concurrent studies on case management and non-case managed patients.

Further research should be done to establish the effects of nursing case management on the care of patients with other diagnoses such as knee and hand surgeries. Studies could be conducted to determine the effect of nursing case management on life style modification. Based on the findings of this study, several questions for further research are generated. Among these are:

1. Does the type of surgical procedure affect patient outcomes?

2. Is there a difference in outcome related to such co-morbidities as Diabetes Millitus. 


\section{REFERENCES CITED}

American Nurses Association. (1991). Nurses Agenda for Health Care Reform. Kansas City: American Nurses Association.

Barangan, J. (1990). Factors that Influence Recovery from

Hip Fracture During Hospitalization. orthopedic Nursing, $\underline{9}(5), 19-30$.

Bower, K., (1988). Case Management: Meeting the Challenge. D.E.F.I.N.I.T.I.O.N. The First Five Years, $\underline{3}(1), 26-28$. Brody, J., (1985). Decreasing Mortality and Increasing Morbidity in the 20th and 21st Centuries. In Reinhard, S., (1988). Case Managing Community Services for Hip Fractured Elders. Orthopedic Nursing, Z(5), 42-49. Brower, G., (1960). Epidemology of Fractures in the Aged Person. Clinical Orthopaedic and Related Research, 17, 219-225.

Chinn, P., Kramer, M. (1991). Theory and Nursing. (3rd ed.) St. Louis: Mosley.

Christinsen, P., \& Bender, L. (1994). Models of Nursing Care in a changing Ėnvironment: Current Changes and Future Directions. Orthopaedic Nursing, 13(2), 64-70. Cronin, C., \& Maklebust, J. (1989) Case Managed Care: Capitalizing on the CNS. Nurse Manager, $20(3), 38-47$. 
Edridge, M. (1987). Nursing Case Management: A Classic. D.F.I.N.T.I.O.N. The First Five Years, 2(2), 16-17. Edridge, M. (1989). Collaborative Care Nursing Case

Management. Chicago: American Hospitals. Farmer, M., White, L., Brodey, J., \& Bailey, K. (1984). Race and Sex Difference in Hip Fracture Incidence. American Journal of Public Health, 74, 1374-1380. Giffen, M., \& Giffen, R. (1994). Critical Pathways Produce Tangible Results. The Newsletter for Hospital Strategies, 12(7), 1-23. Grave, L., Kovner, C., (1986). Communality and Length of Stay. Nursing and Health Care, I(8), 426-430. Grayheal, K., Green, M., \& McKenna, B. (1993). Critical Pathway Development: The Overlake Model. Nursing Management, 24 (4), 42-45.

Grimaldi, P., Micheletti, J. (1985). Prospective Payment: The Definitive Guide to Reimbursement. Chicago: Pleuribus Press.

Hansel, M. (1988). Fractures and the Healing Process. orthopedic Nursing, $7(1), 43-50$.

House of Representative. (1993). Report to the Honorable Ron Winter. United States General Accounts Office. Hussein, T. (1993). The nurse Case Manager in Acute Settings. Journal of Nursing Administration, 23(10), $53-61$. 
Jensen, J. (1980). Incidence of Hip Fractures. ACTA Orthopaedic Scandenavia, 51, 511-513. Jetty, A., Harris, B., Champion, E., \& Cleary, P. (1987). Functional Recovery After Hip Fracture. Archives of Physical Medicine and Rehabilitation, 58, 740-935. Kalisch, P., \& Kalisch, B. (1986). The Advance of American Nursing (2nd ed.). Little: Brown \& Co. Kelsey, J., \& Hoffman, S. (1987). Risk Factor for Hip Fracture. The New England Journal of Medicine, 316(7), 404-406.

Knovner, C., Hendrickson, G., Knickman, J., \& Stevan, F. (1993). Changing the Delivery of Nursing Care. Journal of Nursing Administration, $\underline{23}(11), 24-34$. Lukens, L. (1986). Six Months After Hip Fracture. Geriatric Nursing, $7(4), 202-206$. Mann, A., Hazel, C., Geer, C., Hurley, C., \& Podrapovic, T. (1993). Development of an Orthopedic Case Manager Role. Orthopaedic Nursing, 12(4), 23-62. McKenzie, C., Torkelson, N., \& Holt, M.(1988). Care and Cost: Nursing Case Management Improves Both. Nursing Management, $\underline{20}(10), 30-35$.

Meisler, N., \& Midyette, P.(1994). CNS to Manager: Broadening the Scope. Nursing Management, 25(11), $44-46$. 
Metcalf, E. (1991). The orthopedic Critical Path.

Orthopaedic Nursing, 10(6), 25-31.

Milleson, M. (1988). Nursing Case Management: A Success at Boston Hospital. Health Weekly, 20(3), 20-21.

Newman, B. (1989). The Newman System Model. Norwalk, Ct: Appleton \& Lang.

Nugent, K. (1992). The Clinical Nurse Specialist as Casde Manager in a Collaborative Practice Model: Bridging the Gap Between Quality and Cost of Care. Clinical Nurse Specialist. $6(2), 106-111$.

Nurse Executive News Scan. (1993). Health Care Expenditure. (Audio Tape No. 1). Olivas, G., Deltogno-Armanasco, N., \& Harter, S. (1989). Developing and Integrated Nursing Case Management Model. Nursing Management, 20(10), 26-29. o'Mally, J. (1992). Future Directions: Managing the CostQuality Paradigm. Critical Care Nursing Quarterly, $15(3), 80-85$.

O'Mally, J., Loveridge, C., Cunningham, S. (1989). The New Nursing organization. Nursing Management, 20(2), 29-32.

Peirog, L. (1991). Case Management: A Product Line. Nursing Administration Quarterly, 15(2), 16-20. 
Pelletier, M., (1990). Case Management: Success in a Community Hospital. D.E.F.I.N.I.T.I.O.N. The First Five Years, $\underline{5}(3), 55-56$.

Reinhard, S. (1988). Case Management: Community Service for Hip Fracture Elders. Orthopedic Nurse, 9(5), 42-90. Safriet, B. (1992). Health Care Dollar and Regulatory Sense: The Role of Advanced Practice Nursing. Yale Journal of Regulation, 9, 417-487.

Shamisn, J., Hagen, B., Hu, T., \& Fogarty, T. (1994). The Relationship Between Length of Stay and Required Nursing Care Hours. Journal of Nursing Administration, $\underline{24}(7 \backslash 8), 52-58$.

Shiell, A., Kenny, P., \& Farnworth, M. (1993). Journal of Advance Nursing, 18(9), 1424-1428.

Smeltzer, S., \& Bare, B. (1992). Medical Surgical Nursing.

(7th ed.). Philadelphia: Lippincott.

Smith, G. (1993). Hospital Based Case Management Reshaping

Health Care for the 21 century. Sacramento: CME Resource.

Smith, G., Danforth, D. (1994). Hospital-Based Case

Management: Part I. The Nursing Spectrum, 4(14), 12-14

Stetler, C. (1987). The Case Management Role: A Preliminary Evaluation. D.E.F.I.N.I.T.I.O.N. The First Five Years, $2(4), 23-25$. 
Twyon, S. (1985). Fiscal Environment. D.E.F.I.N.I.O.N. The First Five Years, 1(1), 3-4.

Ward-Evans, S., Hodges, L., \& Smith, J. (1991). The New Role for Neuroscience Nurses: The Case Manager. Journal of Neuroscience Nursing, 23(4), 256-260.

Wimpsett, J. (1994). Nursing Case Management: Outcomes in a Rural Environment. Nursing Management, 25(11), 41-43. Woldum, K. (1987). Critical Paths: Marking the Course. D.E.F.I.N.I.T.I.O.N. The First Five Years, 2 (3), 19-22. Yong, L. \& Haynes, A. (1988). Nursing Administration: From Consept to Practice. Phidelphia: W. B. Saunders. Zander, K. (1985) Defining Nursing... Roots and Wings. D.E.F.I.N.I.T.I.O.N. The First Five Years, 1(1), 1-2. Zander, K., (1987). Nursing Case Management: A Classic. D.E.F.I.N.I.T.I.O.N The First Five Years, $2(2), 16-18$. Zander, K. (1988). Manage Care Within Acute Care Setting: Design Implementation Via Nursing Case Management. Health Care Reform, $6(2), 27-43$. Zander, K., (1988). Nursing Case Management: Strategic Management of Cost and Quality Outcomes. Journal of Nursing Administration, 18(5), 23-30.

Zander, K., (1994). Responsive Restructuring: Turning Care Following into Crae Management Part 3. New Definition, 9(1), 1-3. 
Zindrick, M., Daley, R., Holleyfield, R., (1985).

Femoral Neck'Fracture in the Geriatric Population. Journal of the American Geriatric Society, 33, 104-108. 
APPENDICES 
APPENDIX A

Research Protocol 
1. PROJECT TITE: NURSTNG CASE MANAGEMENT ; A NETH PERSPECTIVE TO CARING FOR PATIENTS WITH HIP FRACTURE.

2. PRDNCIPAL DVVESTIGATOR: BEVERLIN ALLEN S51: $594-10-3471$ Addres 17405 S.W. 108 CT., MTAMI, FL 33157 Phase : 1305$) \quad 232-9036$

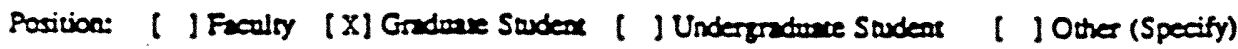

3. FACUITY SURERViSOR (if PI is a souder): LUZ S. PORTER, R,N, , M,S.N., Ph.D.

4. STATUS OF PROTECT REVIEW:

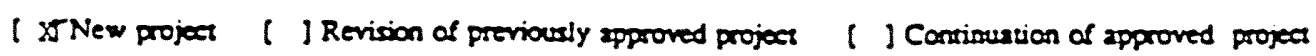

s. BRIEF DESCRIPTION OF SURECTS

Number of subjecer NOT MORE THAN 150

Check all of the following caregories that describe your reserch subjecs:

[Do Males

IXX Females

I I Minars (under 18 yeas ald)

1 I Siudents (Plasese Specify):

(x) Persons With Physial Diabilities (Please Specify): HIP FRACTURE

( I Persons Wilh Menallipsychological Disabilities (Plexe Specify):

(1 I Persons With Prysial or Merod Health Problems (Plecese Specify):

1. Fersons With No Koown Dinabilities and No Known Health Problems

1 I Prisones

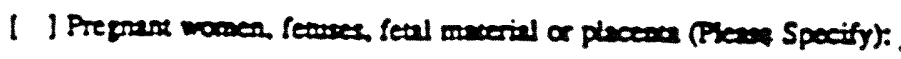

1 I Persons in Some Type of Propren (Fiease Specify):

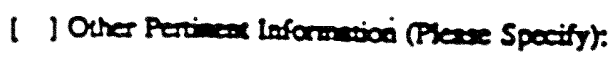

6. TYPE OF REVIEW REQUESTED (See pares 6 \& 7 of the information for Experimenters bootlet): $|x|$ Exemp: Cuepary o(s):

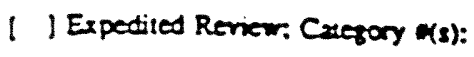

1. I Full URC Renew (Can be neither Exempred nor Expedied) 


\section{AFFIRMATION OF COMPLIANCE AND ACCEPTANCE OF RESPONSIBILTTY}

1 agree 10 follow the procedures oulined in this summary description and any atuchments. I underseand that no consact may be initisied with subjects until thave received approval of these procedures from the URC and have complied with any modifications required in conncetion with thas approval. I understand thas additions to or changes in the procedures involving human subjects can only be made after approval of the URC. I undersind thas I must promply repon to the URC any problems with the rights or welfare of the human subjects I undersand and will follow Florida Intemrional University's policies concening research with human subjects. I will do everything in my power 10 protect the rights and welfare of human subjects in my research project.

Nursing Case Management: A New Perspective to Caring for Patients with (prnit uile of project here) Hip Fracture.

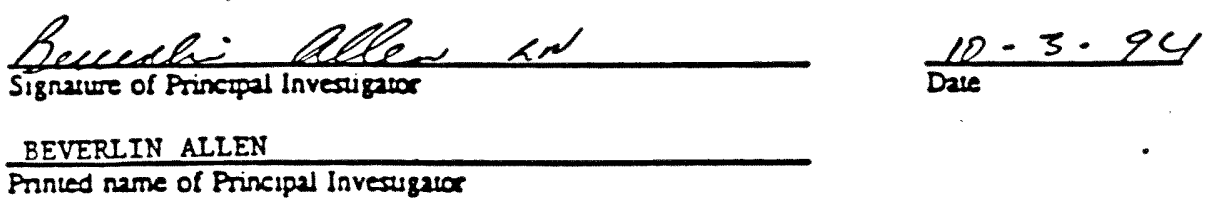

If the PI is a student, the fxulty supervisar mus sign betow.

I have read this application and assume responsibility for its aceurcy and for supervision of the proposed research project

$$
\text { ghe of Pother }
$$

Signaiure of Facufy Supervisor

$$
\frac{10-3-94}{\text { Date }}
$$

LUZ S. PORTER, R.N., M.S.N:, Ph.D.

Printed name of Faculty Supervisor

ACTION RECOMDENDED BY URC *For URC we onty"

Date:

Signasure of URC Creiperion

Prinied name of URC Chaiperson

Date: I I Approved I I Cheseaclarificaions Requested

(I) Require Full Boord Review

Signature of URC Charperson

Date: 1 I Approved I IChrosclarificaions Requesed 
: Before completing the application form carefully read this entire handout. It contains information ahout how to complete the application form and about federal and FIU regulations. When completing the application form please type or print legibly, and write clearly so the committee members can understand what you are doing. The entire application form must be completed: simply referring 10 an altached research or grant proposal is not acceptable. Incomplete applications, incomprehensible applications, and illegible applications will not be reviewcd.

Line-by-line instructions for completing the application are given below. If you have any questions after reading this encire handout the URC chairperson will be happy to answer them.

\section{Instructions for Completion of \\ Application for Approval of Research Involving Human Subjects}

1. If this is a renewal be sure you use the same tide you used in the initial application.

2. The PI is the person whose research will be completed. Provide a home address only if the PI does nat have a campus address.

3. If the PI is a student a faculty member must accept final responsibility for the research project.

4. If this is a renewal be sure the title of this proposal exactly matches the title of the previously approved project.

5. Specify the number of subjects and check all categories that apply.

6. The categories of exempt and expedited review are detailed on pages 6 and 7 of this handout. To receive exempt or expedited review you must check one of these types and enter the appropriate category on the line provided. Note that. despite the name. exempi research must be approved by the URC.

7-14. As indicated. only new information must be provided.

15. The PI must sign here. If the PI is a student, the faculty supervisor also must sign.

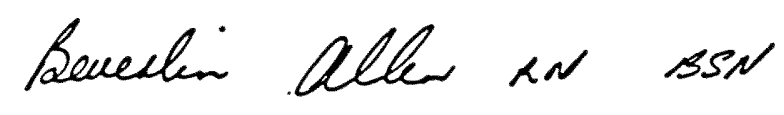




\section{Research Objective:}

Predicated on Betty Newman's theory that a person is an open, unique, holistic system which is subjected to environmental stressors, this study seeks to determine the effects of nursing case management upon the care of patients with hip fractures. Specifically, the study focuses on defining the effects of case management upon patient outcomes in terms of: ambulation, activity of daily living ( $A D L)$, and length of stay ( $L O C$ ).

\section{Subject Recruitment:}

This is a retrospective study which is based on chart review. The population will consist of all patients admitted to Mercy Hospital with a diagnosis of hip fracture. The control group will be comprised of all chart from the pre- case management period January, 1990 to september 1990. Similarly the experimental group will be comprised of all charts from the case management period January, 1994 to September, 1994. Patients with co-morbidities such as altered mental status, and chronic obstructive pulmonary disease (COPD) will be excluded from the study as these diagnosis could significantly affect the results of the study. Because 1991 to 1993 were years of heightened awareness and planning for case management, this period will not be included in the study. 


\section{Benefits:}

There are no financial or other extrinsic renumerations to potential subjects in this study. However, the financial incentives to hospitals are clear since a hospital gets a lump sum based on a particular DRG. Case management, through promotion of efficient utilization of services can result in reduction of length of stay thereby conserving the hospital revenue.

Consumers are empathic about the need to hold costs and improve the quality of care provided to patients. Case management is likely to improve quality of care by reducing fragmentation in health care, and by providing consistency for families and patients. Its focus on clinical and social needs is designed to meet specific outcomes for the individual population (Pelletier, 1990).

Metcalf (1991) stated that the case management model requires nurses to utilize management skills such as controlling, delegating, directing, and collaborating with patients and other professionals. These responsibilities could afford nurses greater autonomy over patient care. Through case management nurses influence the hospital in areas of patient care and cost containment, thereby facilitating greater control over clinical and financial outcomes of patient care. The increased opportunity may promote professional development and satisfaction of 
hospital-based registered nurse. Results of studies done on case management could be used in advancing nursing practice. 10. Informed Consent:

As this is a retrospective study comprising of chart review only, informed consent will not be necessary. However, institutional consent will be sought by submitting this proposal to the research committee at mercy hospital. 11. Confidentiality of Data:

To safeguard confidentiality, all data will be coded and stored safely in a locked filing drawer accessible only to the investigator. Research findings will be reported in terms of group phenomena and no reference will be made to identify any particular subjects. Coded raw data will be accessible only to the principle investigator, statical consultant, and the major professor.

\section{Method and Procedures:}

Study patients will comprise of those admitted to Mercy Hospital with a diagnosis of Hip Fracture. The investigator will obtain from the operating room the names of all patients who have had repair of hip fracture during the periods to be investigated. With the exception of patients with history of altered mental status, morbid obesity, and chronic obstructive pulmonary disease (COPD); all patients will be included in the study regardless of individual variables such as age, sex, and physical fitness. 
Patient's ability to perform activities of daily living will be assessed according to the Patient care Flow sheets and Systems Assessment Sheets. Particular attention will be placed on nutrition ( ability to self-feed), hygiene, activity, and musculo skeletal neuro assessment. Additionally, nursing notes, and physical therapy notes will be reviewed. Length of Stay (LOS) will be measured by counting the number of days from admission to day of discharge.

To determine the effect of case management on patient outcomes, inferential statistics will be used to provide a means for testing the hypothesis. In addition differences between the group means will be tested using the t-test. The level of significance is set at 0.05 for the study.

\section{Stimulus Materials:}

See attached Copies.

\section{Risk To Subjects:}

There are no known immediate or long range physical, psychological, or social risks to subjects that may arise from this study. 
Metcalf, E. (1991). The Orthopedic Critical Path.

Orthopaedic Nursing, 10(6), 25-31.

Newman, B. (1989). The Newman System Model. Norwalk, Ct:

Appleton \& Lang.

Pelletier, M., (1990). Case Management: Success in a

Community Hospital. D.E.F.I.N.I.T.I.O.N. The First

Five Years, $\underline{5}(3), 55-56$. 
APPENDIX B

INSTITUTIONAL APPROVAL

FLORIDA INTERNATIONAL UNIVERSITY IRB

MERCY HOSPITAL 


\section{FLORIDA INTERNATIONAL UNIVERSITY DIVISION OF GRADUATE STUDIES THESISIDISSERTATION COMMITTEE APPOINTMENTS}

ALL INFORMATION MUST BE TYPED

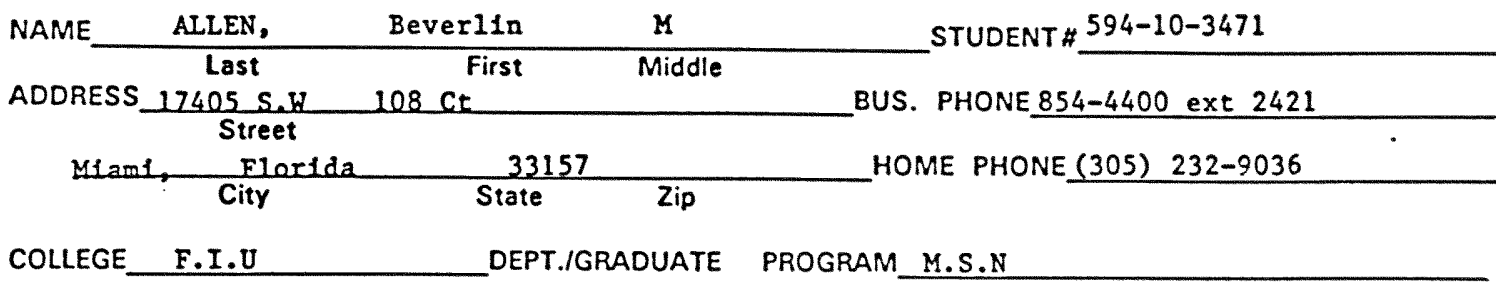

FIRST ENROLLED AS DEGREE SEEKING
DATE $\quad 10-3-94$

Ph.D. ( )

THESIS $\mathrm{X})$ DISSERTATION $(1$ AREA

DATE OF PREVIOUS COMMITTEE APPOINTMENT

N/A - (If any.)

COMMITTEE: The signatures of the faculty below affirm that they met with the student, reviewed the topic and agree to serve on the committee. (PLEASE TYPE ALL NAMES \& SIGN)

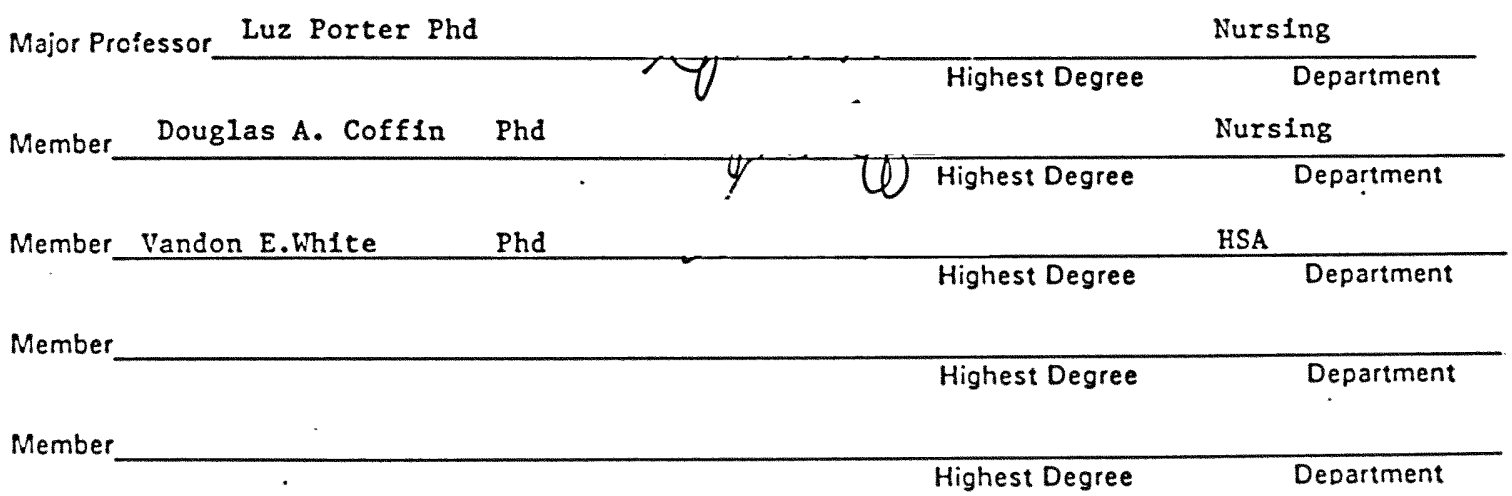

COMMITTEE REQUESTED BY:

\section{Student Signature}

COMMITTEE RECOMMENDED BY:

$$
\text { A Chairpersah/Program Director }
$$

APPROYED BY:

fPSO. Dean of Collede or School

APPROVED BXuz Porter

$$
\text { Dean of Graduate Studies }
$$

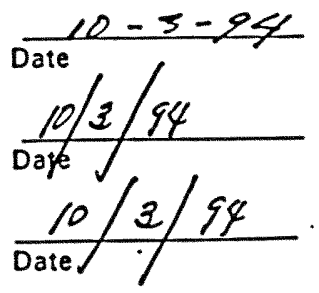

\section{Date}

DISTRIBUTION:

White: Graduate Studies Yellow: Academic Dean Pink: Coord. of Grad.lDoctoral Studies Gold: Student $1 / 11 / 93$ 


\section{(min) Mercy}

November 22,1994

Mrs. Beverlin Allen, R.N., B.S.N. Graduate Student

Florida International University

Dear Mrs. Allen:

Thank you for submitting an application for approval of your research project "Nursing Case Management: A New Perspective to Caring for Patients with Hip Fracture." I am pleased to inform you that your proposal has been unanimously approved by the Nursing Research Committee.

Please let us know when you bil.1 begin and complete your study. We are also requesting updates on your progress and a summary report at the end of your research.

If you need any further assistance, we will be available to help you. please call me at ext. 2154. Best wishes as you proceed with your research study.

sincerely,

Dyrie Francis, R.N., M.S.N., CCRN Committee Chairperson 
APPENDIX C

DATA COLLECTING TOOLS

PATIENT CARE FLOW SHEET

PATIENT CARE ACTIVITY AND ASSOCIATED RESPONSE PERIODS CRITICAL PATHWAY FOR HIP FRACTURE 


\section{Th Mercy Hospital \\ soss SOUTW MIAMI AVENUE \\ minus ronioa z3is3 \\ PATIENT CARE FLOW SHEET}

DATE:

\begin{tabular}{|c|c|c|c|c|}
\hline \multirow{17}{*}{$\frac{z}{\underline{E}}$} & DIETTYPE & $B K=$ & & D \\
\hline & ATEALLFOOD SERVEO & 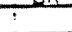 & & \\
\hline & ATE APPROX Y Y FOOO SERVED & $\div$ & & $i$ \\
\hline & ATE VERY LTTTLE & & & $T$ \\
\hline & REFUSEDTRAY & & & $T$ \\
\hline & NPO & & & 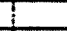 \\
\hline & SELF.FEED & $\vdots$ & & 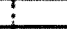 \\
\hline & FEED WIASSISTANCE & & & 1 \\
\hline & COMPLETEFEED & $\dot{-}$ & & $T$ \\
\hline & TUBEFEEOING - TYPE & o & $\boldsymbol{E}$ & $\mathbf{N}$ \\
\hline & NASOGASTRIC & & & $T$ \\
\hline & GASTROSTOMY & $T$ & & $T$ \\
\hline & INTERMITTENT & 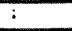 & & 1 \\
\hline & CONTINUOUS PUMP & & & 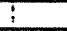 \\
\hline & TPN & & & 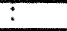 \\
\hline & FLUIORESTRICTION.AMT. & & & \\
\hline & FORCE FLUIDS - AMT. & ? & & $!$ \\
\hline \multirow{10}{*}{$\frac{u}{u}$} & SELFCARE & & & I \\
\hline & BATHWIIASSISTANCE & $i$ & & 1 \\
\hline & COMPLETE BEDBATM & $!$ & & 1 \\
\hline & SPECIAL SKIN CAREIKIT & $\overline{1}$ & & $\vdots$ \\
\hline & BACK CARE & $\bar{Z}$ & & $\bar{\vdots}$ \\
\hline & FOOT CARE & $i$ & & 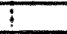 \\
\hline & PERICARE & $\bar{i}$ & & $T_{1}^{1}$ \\
\hline & MOUTHCARE & 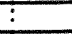 & & \\
\hline & H.S.CARE & $T$ & & $\bar{z}$ \\
\hline & OTI ER SHAVES SHAMPOOINAIL CARE & $i$ & & T \\
\hline \multirow{10}{*}{$\frac{2}{5}$} & AMBULATORY & I & & \\
\hline & OOB WIASST CHAIRIAMUUUHOYER & 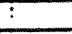 & & \\
\hline & BRP WIASSISTANCE & $!$ & & \\
\hline & BEOREST & & & \\
\hline & TURNS SFLF & & & \\
\hline & TURN B POSITICN O - MRS & & & \\
\hline & TIME: $\quad T=B A C K \quad=A B D$ & 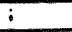 & & \\
\hline & -1 SIDE & 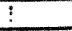 & & \\
\hline & ROM.RED CHAIR EXERCISES & $i$ & & \\
\hline & TURN COUGH DEEP BREATHE & $\bar{z}$ & & \\
\hline \multirow{9}{*}{ 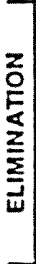 } & STOOUINCONTINENT I TIMES & & & \\
\hline & VOIOINGINCONTINENT I TIMES & & & \\
\hline & INCONTINENTPAD:TYPE. & 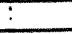 & & \\
\hline & FOLEY CATHETER & & & \\
\hline & HEMOVACISP. & & & \\
\hline & NASOGASTRIC TUBE & & & \\
\hline & SUCTIONGOMCONALL & & & \\
\hline & OSTOMY.TYPE & & & \\
\hline & OTHER.TYPE & & & \\
\hline \multirow{10}{*}{ 荘 } & UPPER BEDRAILS UP & & & \\
\hline & LOWER BEDRAILS UP & & & \\
\hline & BEDEXITALARM ON & & & \\
\hline & RESTRAINTS APPLIEDIRELEASED & & & \\
\hline & TYPE: & 7 & & \\
\hline & CALLLIGHTIN REACHIFUNCTIONING & & & \\
\hline & ISOLATION.TYPE & & - & \\
\hline & AWAKE & & & \\
\hline & SLEPTATINTERVALS & . & & \\
\hline & SLEPT WELL & & & \\
\hline
\end{tabular}

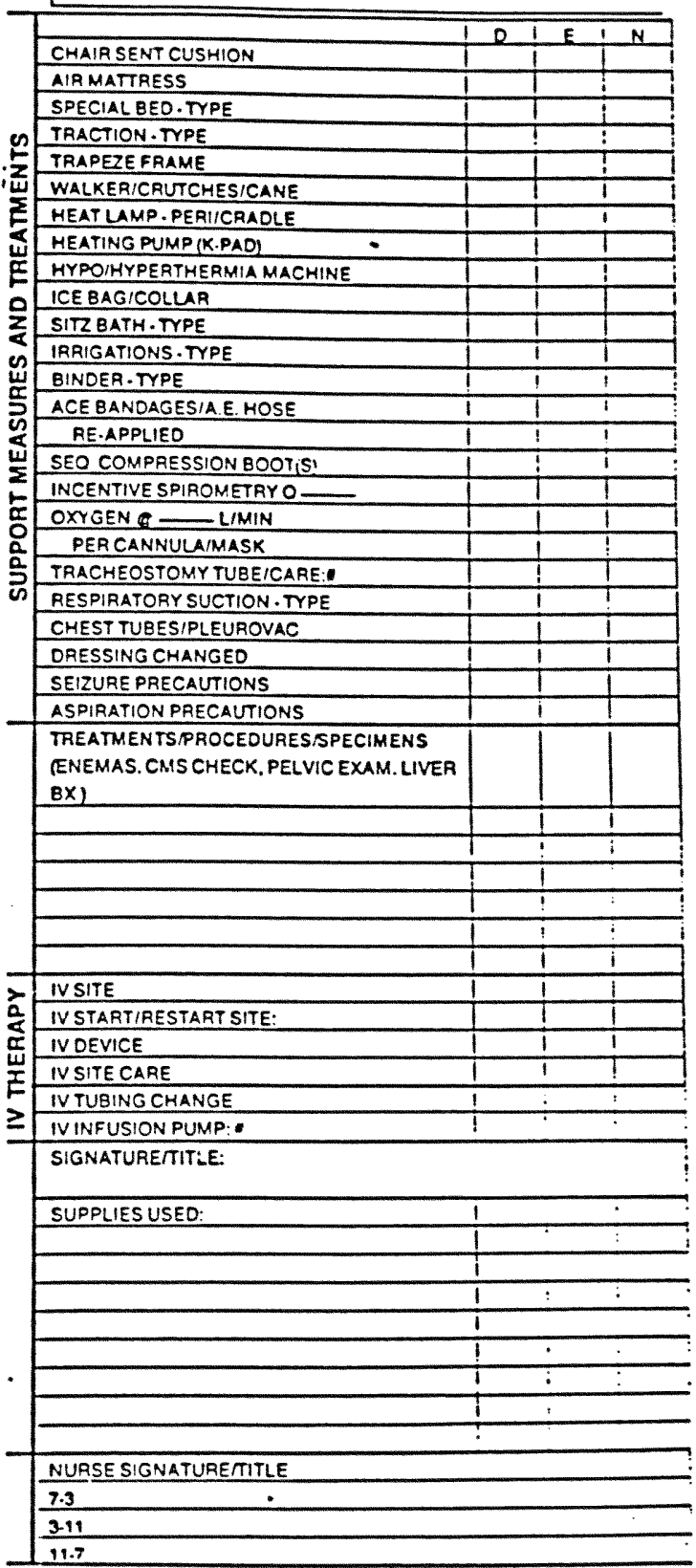




\section{Patient Care Activities and Associated Active Response Periods Year:}

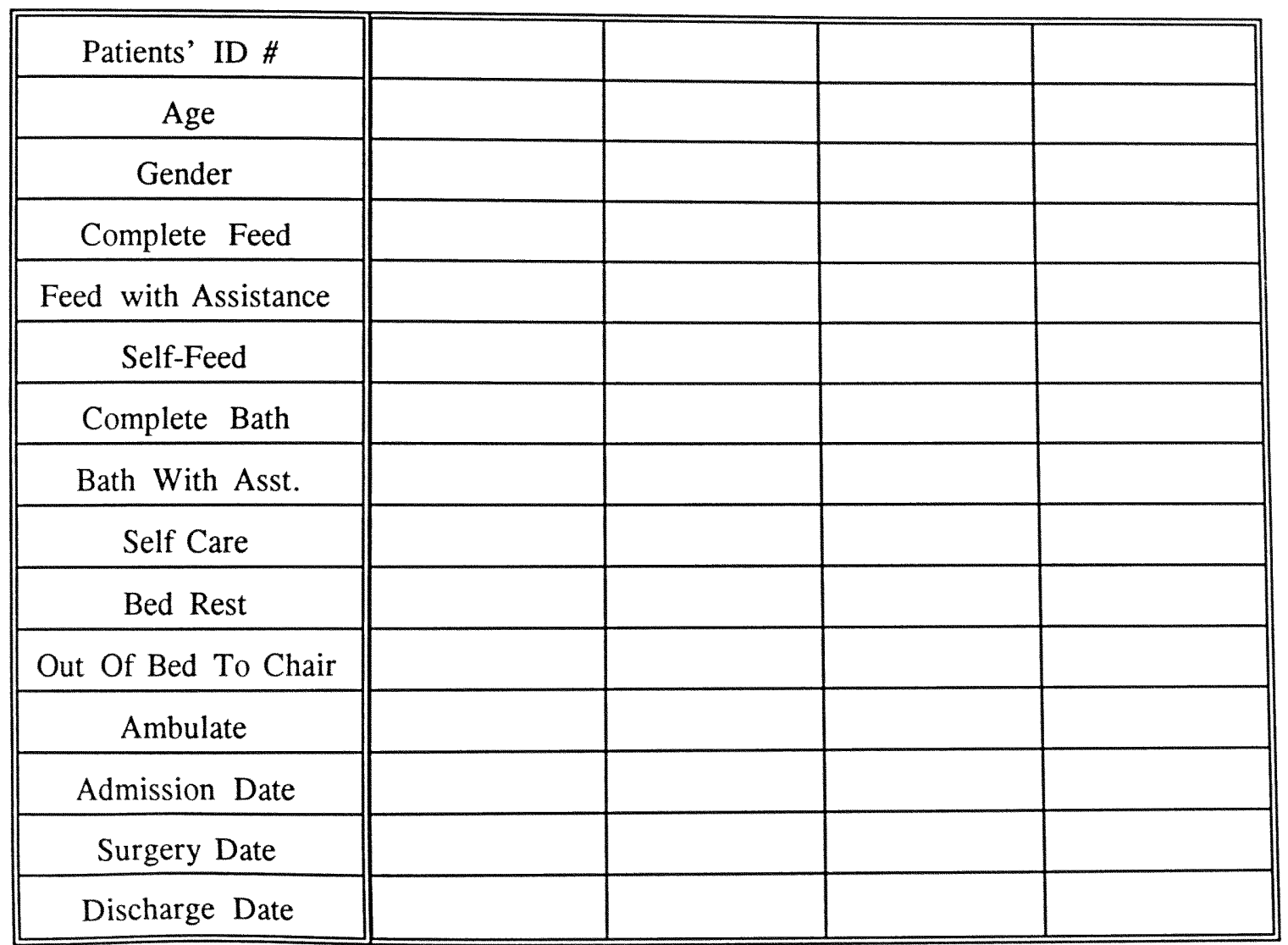




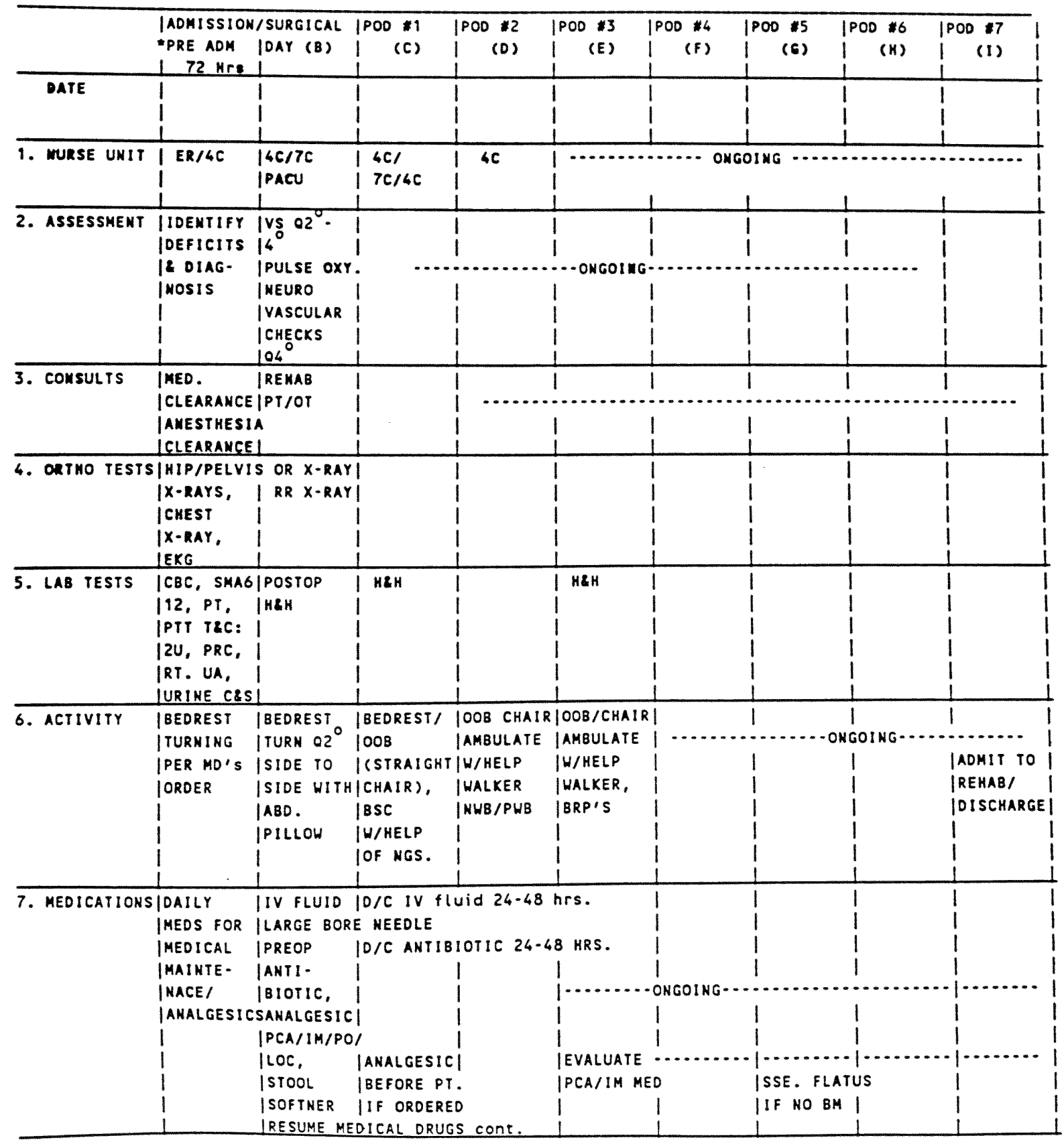




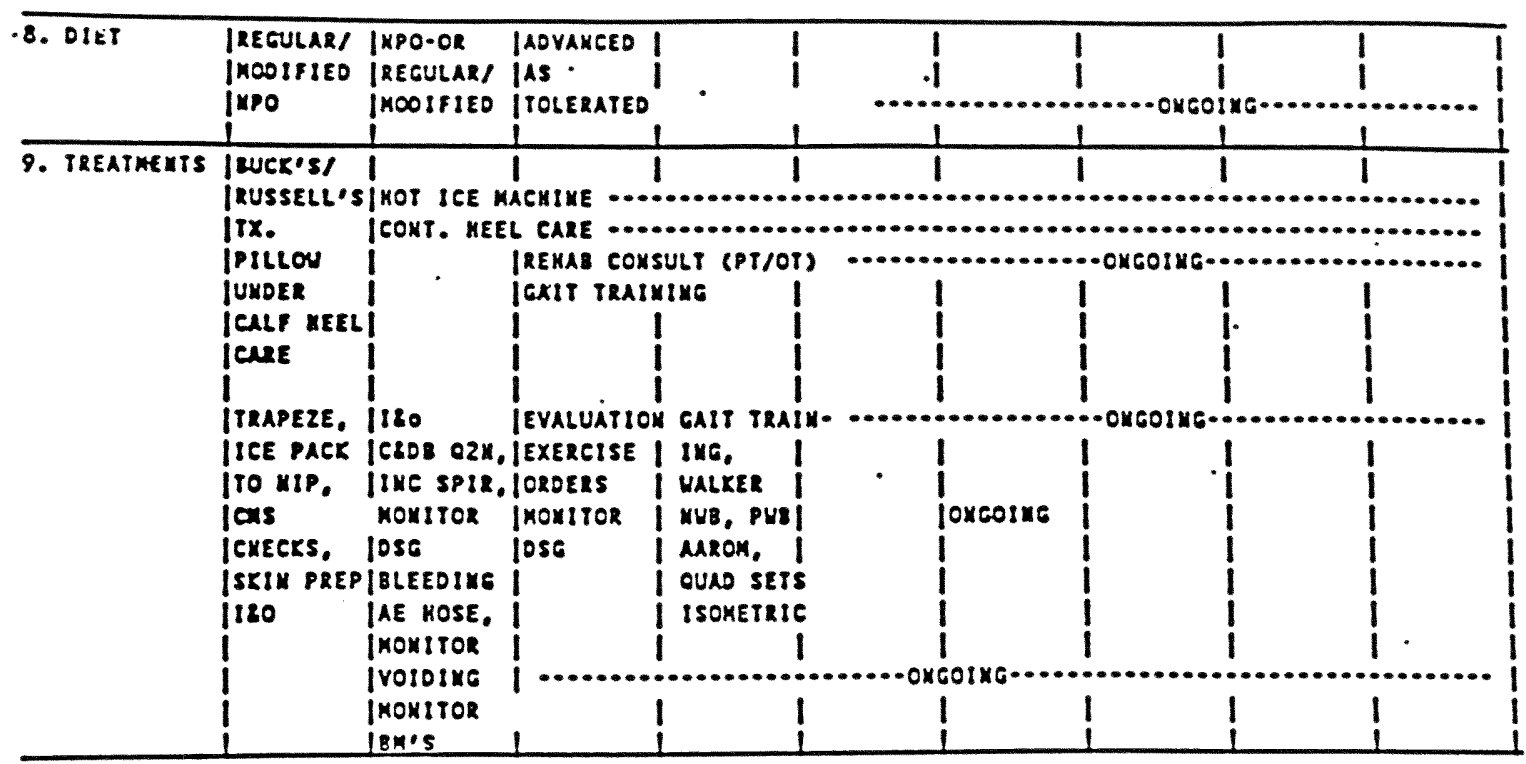

